\title{
Auditory and visual serial position functions obey different laws
}

\author{
ANTHONY A. WRIGHT \\ University of Texas Medical School, Houston, Texas
}

\begin{abstract}
Rhesus monkeys were tested in serial probe recognition tasks with either travel slide pictures or natural sounds. Tests with four-item lists produced serial position functions that were essentially opposite in shape for the two modalities and changed in opposite ways with retention interval. For visual memory, the primacy effect grew and the recency effect dissipated with retention interval. Capuchin monkeys, humans, and pigeons showed similar results. For auditory memory with rhesus monkeys, the recency effect grew and the primacy effect dissipated with retention interval. These results taken together, along with results from rehearsal tests of monkeys and humans, implicate two passive memory processes with different time courses. Interference among items within auditory lists was manipulated by varying the time between items and categories of items. Interference across lists was manipulated by varying the item pool size and, hence, item repetitions. Changes in the auditory serial position functions indicated that proactive and retroactive interference may have been instrumental in these dynamically changing serial position functions. Implications for theories and models of memory are discussed.
\end{abstract}

The focus of this article is on visual and auditory list memory experiments with rhesus monkeys that my collaborators and I have conducted over the past 20 years. It took us several years to develop visual list memory procedures in which monkeys would perform at a high level of accuracy. Even more years were spent developing adequate auditory list memory procedures. Considerable development was required before the monkeys learned even the basic rudiments of the auditory task. Experiments from both tasks revealed serial position functions that changed in an orderly fashion across a range of retention intervals. The shapes were, however, different and essentially opposite for the two modalities. These results and others may be revealing about some of the basic mechanisms of short-term recognition memory in monkeys. Some aspects may be relevant for human memory. Similar visual memory findings have been shown for humans as well as rhesus monkeys, capuchin monkeys, and pigeons.

\section{RATIONALE FOR TESTING MONKEY LIST MEMORY}

List memory is perhaps best characterized by the serial position function. Memory is typically found to be best for the first items of a list (primacy effect) and the last items of a list (recency effect) and poorest in the middle. This U-shape

This research was partially supported by PHS Grants MH-35202 $\mathrm{MH}-54167$, and DA-10715. The author gratefully acknowledges the careful assistance of Jackie Rivera and the help and encouragement on the manuscript from Roddy Roediger, Endel Tulving, Michael Watkins, and an unidentified reviewer. Reprints may be obtained from the author at University of Texas Medical School at Houston, Department of Neurobiology and Anatomy, P.O. Box 20708, Houston, TX 77225 (email: aawright( $u$ nbat 9.med.uth.tmc.edu). has long been the benchmark of list memory (Ebbinghaus, 1902). One focus of the vast amount of research conducted on list memory has been on selective elimination of either the primacy or the recency effect. For example, the recency effect can be selectively eliminated by delaying the test (see, e.g., Glanzer \& Cunitz, 1966), whereas the primacy effect can be selectively eliminated with alcohol (see, e.g., Jones, 1973). An implication of such dissociations is that the serial position function is composed of different underlying memory processes or mechanisms. Nevertheless, the nature of these processes remains uncertain.

The purpose of the research summarized in this article was to study similar or related memory processes in rhesus monkeys. Using monkeys, rather than humans, in behavioral memory tests has several potential advantages. (1) Short lists can be used without encountering ceiling effects. Tests with short lists may be essential in the study of some changes in serial position effects because they may be unobservable with longer lists. (2) The monkey's strategic processing (e.g., coding, rehearsal, etc.) can be assumed to be comparatively limited, thus eliminating these potentially confounding influences and their use as explanatory devices. (3) Once trained, monkeys can be tested daily for years in many different experiments and parametric manipulations. As a practical matter, seldom are such extensive within-subjects experiments conducted with humans.

These advantages notwithstanding, an obvious disadvantage in using monkeys is the large amount of time required to develop memory procedures and to train them in the tasks.

\section{VISUAL MEMORY PROCESSING}

We began our visual memory experiments by training a rhesus monkey with 211 pictures (Sands \& Wright, 
1980a, 1980b). Most pictures had a main object, some of which were familiar (e.g., apples) and some unfamiliar (e.g., flowers). In basic training on the procedure, the monkey pushed down on a three-position lever (" $T$ " pattern) to start trials. Pairs of pictures were presented, and the monkey moved a lever to indicate that the two pictures were same (right movement) or different (left movement). The monkey mastered this same/different task after 3 months of training, or approximately 28,000 trials. The procedure was then changed to successive presentation of the two pictures. The first picture was removed from the upper screen before the second picture was displayed in the lower screen. Once this task had been mastered, the first item (upper screen) was gradually expanded into a 10 -item list. Items were presented for $1 \mathrm{sec}$, with a 0.8 -sec interstimulus interval (ISI) and a $1-\mathrm{sec}$ retention interval. If the probe item (lower screen) matched any one of the list items shown in the upper screen, a same response was correct. If it matched no list item, a different response was correct. These changes from a simultaneous same/different task to a 10-item serial probe recognition (SPR) task caused surprisingly little disruption of performance. We conducted over 16,000 trials with each of the 211 items tested in each of the 10 serial positions. Performance was $86 \%$ correct with these 10 -item lists. It was even a respectable $81 \%$ correct in an experiment with 20 -item lists. Serial position functions from these experiments are shown in Figure 1. These serial position functions show primacy and recency effects that are similar to those shown for humans.

Shorter lists were used to conduct retention tests with other rhesus monkeys (Wright, Santiago, Sands, Kendrick, \& Cook, 1985). The four-item lists were originally chosen in order to make a direct comparison with fouritem list memory experiments with pigeons. The real benefit from using short lists, but one that was not apparent at the time, was that short lists allowed changes in serial position functions to be observed that might not have been observed with much longer lists. The four pictures of each list were presented for $1 \mathrm{sec}$, with a $1-\mathrm{sec}$ ISI between

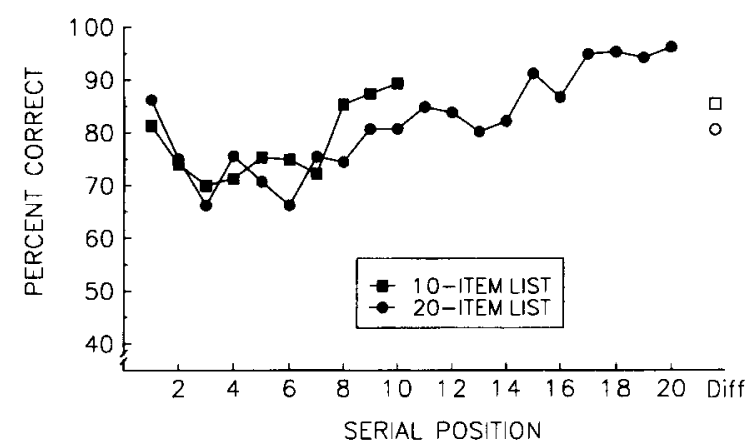

Figure 1. Serial position functions for a rhesus monkey, Oscar, with 10 list items (squares) and with 20 list items (circles). (Serial Position 1 is the first item in the list.) Performance on different trials (Diff), shown to the right, is for trials in which the probe items matched no list item (after Sands \& Wright, 1980b). them. Retention intervals were fixed for a block of 20 trials, and two blocks with different retention intervals were tested daily. Four randomized blocks of six retention intervals were tested.

The results for the rhesus monkeys are presented in the top row of Figure 2. Each individual panel shows a serial position function for a different retention delay between the end of the list and the test. Clearly, the functions change systematically with retention interval. At the shortest delay, the serial position function is upward sloping, dominated by recency. As the delay is increased, primacy appears, giving the function a U-shape, the characteristic shape of serial position functions. At the longest delays, recency drops out, producing downward-sloping functions dominated by primacy.

Capuchin monkeys, pigeons, and humans were tested in similar experiments, under similar conditions. Pigeons and capuchin monkeys were tested with travel slide pictures, and humans were tested with kaleidoscope pattern pictures. The kaleidoscope patterns were distinctly different, while, at the same time, they served to avoid ceiling effects that would have been produced by travel slide pictures. As is shown in Figure 2, the same qualitative pattern of changes in the serial position function shown for rhesus monkeys was shown for these other species. Recency dominates at the shortest retention intervals. Primacy appears with longer retention intervals, producing a U-shaped serial position function. And eventually, recency dissipates, and primacy dominates. But the time courses of these changes in primacy and recency effects were different for different species. With regards to the recency effect, these changes take place in about $30 \mathrm{sec}$ for rhesus and capuchin monkeys, whereas only $10 \mathrm{sec}$ are required for pigeons and $100 \mathrm{sec}$ for humans. With regards to the primacy effect, capuchin monkeys and humans show development of a primacy effect at the 10-sec delay, whereas rhesus monkeys and pigeons show its development at the 1-sec delay.

These absolute values are, of course, particular to these testing conditions and will, in all likelihood, change for other conditions and contexts. Indeed, differences in the values across species will be valid to the degree that the testing conditions across species are similar.

Nevertheless, the similar pattern of changes is striking. An overarching theme of this research is that the pattern of changes is a fundamental signature of the underlying processes in recognition memory. The similar pattern of changes for visual recognition memory indicates that the mechanisms of visual recognition memory are similar in these species.

\section{PASSIVE MEMORY PROCESSES AND THE PRIMACY EFFECT}

Hypotheses concerning processes that have been thought to produce primacy effects can be divided into active versus passive processes (see, e.g., Crowder, 1969, 1976; Tulving, 1968) and willful versus nonwillful processes 

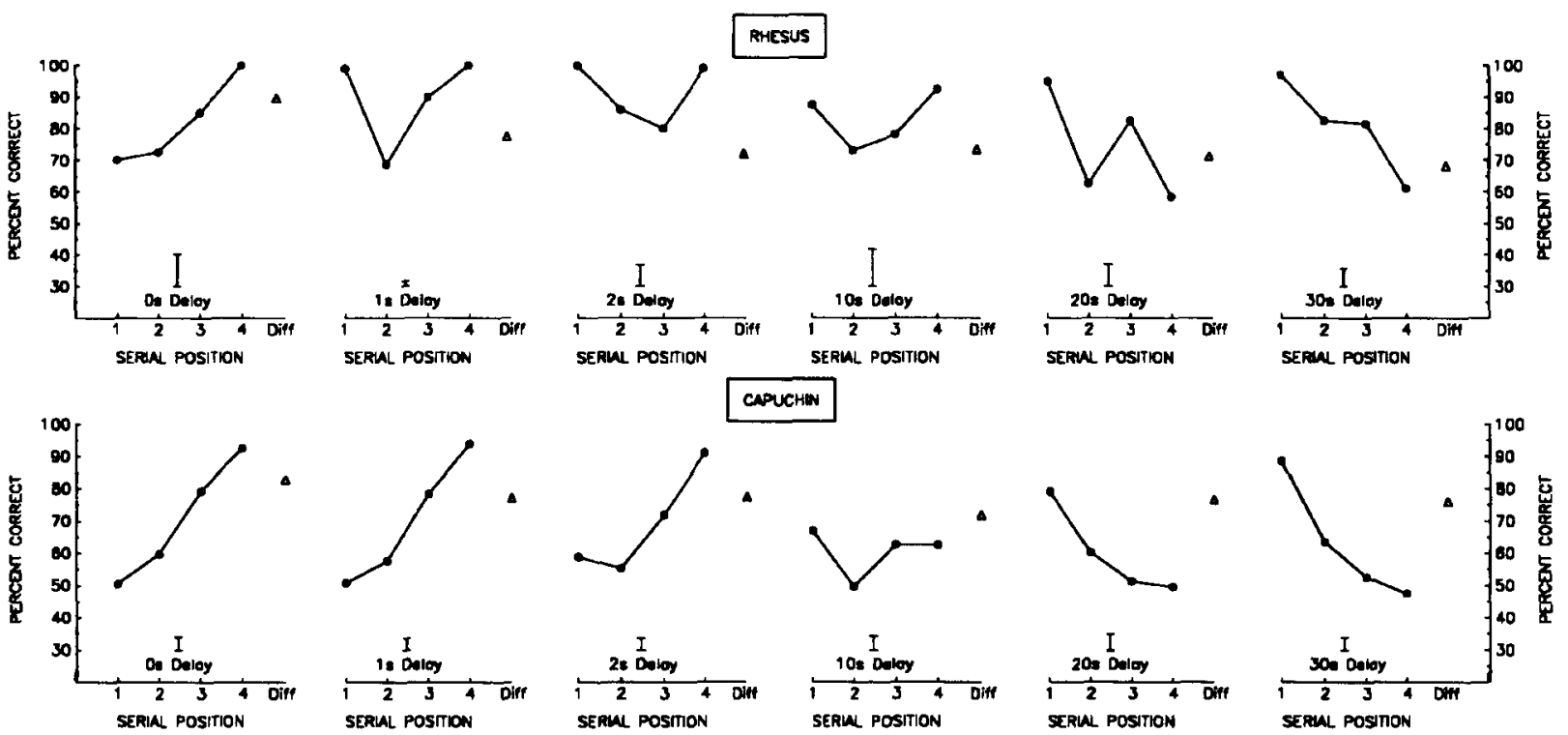

SEREL POSIIION
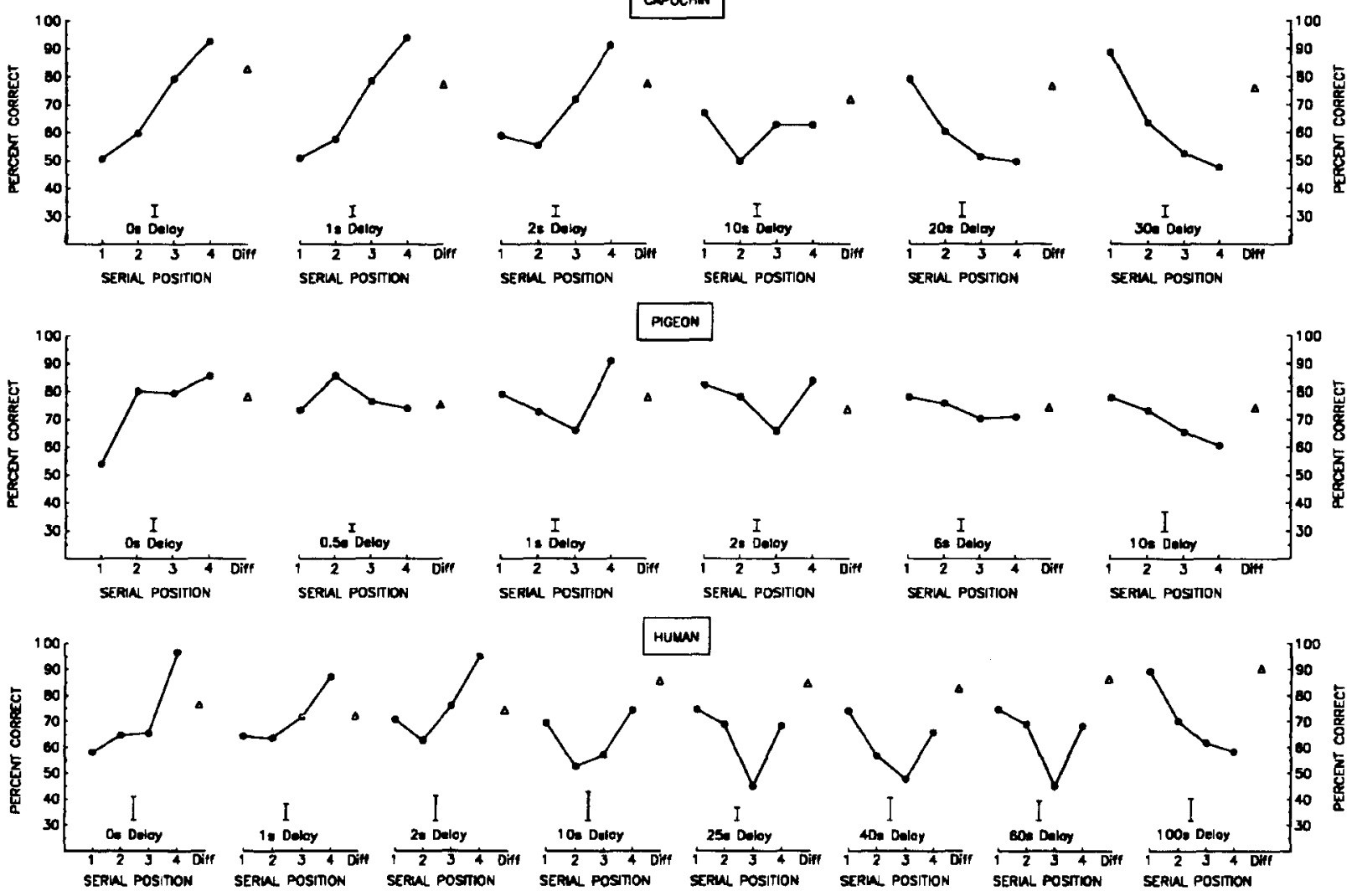

Figure 2. Average performance for rhesus monkeys, capuchin monkeys, pigeons, and humans. Delay is the retention interval between the last list item (Serial Position 4) and the test. Unfilled points (Diff) are performances on trials in which the test matched no list item. Error bars are the average standard error of the mean for the four serial positions of each function (after Wright, in press-b, and Wright et al., 1985).

(Watkins, 1989). Either distinction is considered adequate for the purposes of this article. I consider the critical variable to be the presence or absence of strategic processing. The passive or nonwillful processes can be thought of as occurring virtually automatically in the course of learning, remembering, recognizing, deciding, and responding. A prominent example of passive memory processes is interference (see, e.g., Foucault, 1928; Hull, 1935). The active or willful processes are strategies (actively, willfully) employed by the subject to better remember. Historically, the most prominent has been rehearsal. In its most influential form, the modal model, items enter a short-term limited capacity memory (Atkinson \& Shiffrin, 1968;
Waugh \& Norman, 1965). Rehearsal of items in shortterm memory (STM) transfers them to long-term memory (LTM). Since the first list items receive a disproportionate amount of rehearsal, these items are more likely to be in LTM. It then follows from the theory that the primacy effect represents LTM. A variety of indirect evidence, including transformation of covert rehearsals into overt rehearsals (Rundus, 1971), encouraged pursuit of an active rehearsal hypothesis for the primacy effect.

In addition to evidence that raises serious doubts about the existence of a limited capacity STM buffer (see Crowder, 1993, and Greene, 1992, for reviews), recent demonstrations of animal primacy effects should raise 
concerns as to whether rehearsal is necessary to produce serial position primacy effects. Animals, I think it would be fair to say, would be much less likely than humans to engage in active, willful rehearsal of list items. Animals for which serial position primacy effects have been shown include apes (Buchanan, Gill, \& Braggio, 1981), rhesus monkeys (Castro, 1995,1997; Castro \& Larsen, 1992; Sands \& Wright 1980a, 1980b; Wright, 1998, in press-a; Wright, Santiago, \& Sands, 1984; Wright et al., 1985), squirrel monkeys (Roberts \& Kraemer, 1981), capuchin monkeys (Wright, in press-b), rats (Bolhuis \& van Kampen, 1988; Harper, McLean, \& DalrympleAlford, 1993; Kesner \& Novak, 1982; Reed, Croft, \& Yeomans, 1996), and pigeons (Santiago \& Wright, 1984; Wright et al., 1985).

Supporters of the modal model could, of course, argue that animals could actively rehearse the items even without the benefits of language for coding and strategic processing. In order to provide a more definitive resolution of this issue, we set out to test our monkeys for rehearsal in this list memory task. To do so, we needed an objective test for rehearsal. An objective procedure had been developed to test human rehearsal. In this procedure, the blank time, or ISI, between list items is manipulated. Rehearsal is identified as an increase in accuracy with longer ISIs. Intraub (1980), for example, presented humans with lists of 16 pictures. With a short $(110-\mathrm{msec})$ viewing time and no ISI, performance was only slightly above chance. As the ISI lengthened, performance improved. As the ISI approached $5 \mathrm{sec}$, performance was almost as accurate as when the picture was presented for the entire 5-sec interval. This blank-time, or ISI, effect has been shown to be robust and reproducible. It has also been shown to be under voluntary control of the subject, ruling out involuntary physiological effects, such as consolidation (see Graefe \& Watkins, 1980; Proctor, 1983; Watkins \& Graefe, 1981). Most important for the purposes here, it is an objective procedure that can be used to test animals for rehearsal.

We used the ISI procedure to test rhesus monkeys for rehearsal with six-item lists of travel slide pictures (Cook, Wright, \& Sands, 1991). The results are shown in Figure 3. Performance decreased with ISI and, thus, revealed no evidence of rehearsal by monkeys in this task. One implication of these results is that the primacy effects for rhesus monkeys shown in Figures 1 and 2 likewise were not the result of rehearsal.

Since the monkey's primacy effects are unlikely to be due to rehearsal, it is only natural to speculate about the role rehearsal might play in primacy effects for humans. Humans were tested in the same experiment with the same procedure, items, and sequences as the monkeys (Wright, Cook, et al., 1990). As Figure 3 shows, humans showed prominent ISI effects and, hence, rehearsal with the same travel slide pictures for which the monkeys showed no rehearsal. This result could mean that rehearsal plays a role in primacy effects for humans but not for monkeys. On the other hand, rehearsal might be occurring with hu-

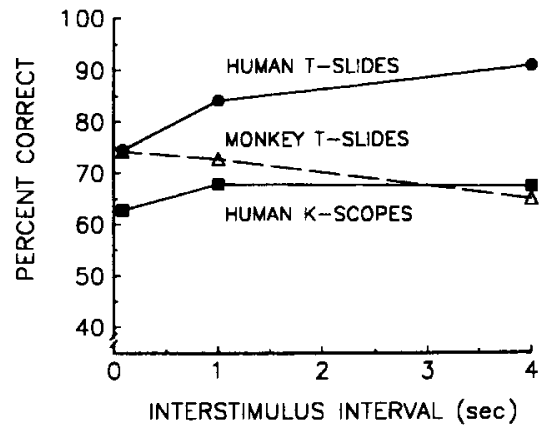

Figure 3. Percentage correct as a function of the interstimulus interval for monkeys tested with lists of six travel slide pictures and for humans tested with the same travel slide picture lists or with kaleidoscope pattern picture lists (after Cook et al., 1991, and Wright, Cook, et al., 1990).

mans but not be instrumental in producing the human primacy effects. To explore this issue, we switched from travel slides to kaleidoscope pictures. Kaleidoscope pictures would be less likely to be rehearsed by humans, because they are difficult to label or code. But humans do show primacy effects with kaleidoscope pictures after delays of $10 \mathrm{sec}$ or more (Figure 2, bottom). Primacy effects have also been shown for other difficult-to-label items, such as snowflake patterns (Neath, 1993b) and antique car drawings (Korsnes, 1995; Korsnes \& Gilinsky, 1993). If humans tested with kaleidoscope pictures produced no ISI effect but did produce primacy effects, rehearsal could not be instrumental in these primacy effects.

Kaleidoscope patterns were tested in place of the travel slides in the previously described ISI experiment (Wright, Cook, et al., 1990). As is shown in Figure 3, there is no (statistically significant) increase in performance with ISI and, hence, no rehearsal with kaleidoscope patterns. Thus, this ISI experiment with humans showed that primacy effects (see, e.g., Figure 2) occur in the absence of rehearsal (see also Greene, 1986; Neath, 1993a). Because rehearsal was absent, we wanted to add rehearsal to this memory task and determine where, in the serial position function, rehearsal might have its effect.

Humans were trained to name 32 kaleidoscope patterns (Wright, Cook, et al., 1990). Naming the items was considered a prerequisite for rehearsal. Other humans served as controls for exposure to the items and rated the proportion of four colors in each picture, to minimize personal labels. Postsession interviews aided in grouping of the subjects according to the type or lack of rehearsal. One group (the chaining group) chained together names of successive list items and rehearsed the chain during ISIs. Another group (the repeating group) repeated only the name of the just-presented item during ISIs. A third group (the sensory group) did neither and instead relied on their "sensory experience."

Figure 4 shows that there was a prominent ISI effect for the chaining group, no ISI effect for the sensory group, and an intermediate ISI effect for the repeating group. 


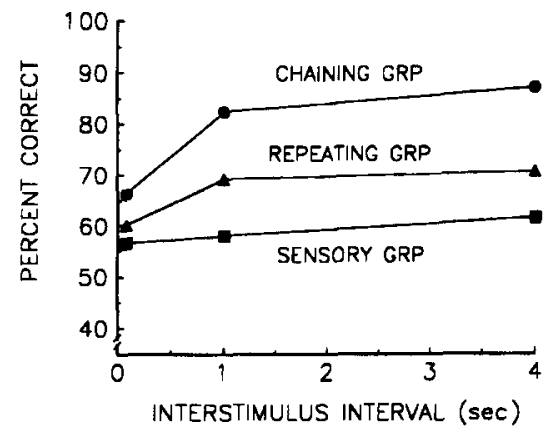

Figure 4. Percentage correct as a function of the interstimulus interval for humans tested with kaleidoscope pattern pictures and grouped according to rehearsal strategy (after Wright, Cook, et al., 1990).

Interestingly, all the groups produced prominent primacy effects. Indeed, there was little difference among groups in their first-item (or last-item) performance, as is shown in Figure 5. Rehearsal did help the chaining strategy group's overall performance, as the ISI effect for this group would indicate. However, rehearsal aided retention primarily in the middle (dip) of the serial position function. If the measure of primacy were the slope of the descending (first) limb of the function, the sensory strategy group would be shown to have the greatest primacy effect and the chaining strategy group the least primacy effect. This is the opposite result that would be expected according to the rehearsal hypothesis of primacy. The rehearsal hypothesis would predict prominent primacy effects for the chaining strategy group and no primacy effects for the sensory strategy group.

Clearly, rehearsal is not instrumental in producing these primacy effects. The uncodeable nature of the items used in these tests of human memory in which primacy effects are found argues for passive processes producing them. Animal memory experiments provide additional evidence for passive processes being instrumental in producing primacy effects. Indeed, it would seem that the serial position function changes with retention interval that are seen in Figure 2 would, in themselves, argue for passive, as opposed to active, strategic processes. There is a gradual shift from a serial position function dominated by recency to a function dominated by primacy. If primacy were based on an active rehearsal process during list presentation, primacy might be expected to be present at all retention intervals. But primacy, like recency, changes over time. The similar changes in primacy (and recency) for the different species, shown in Figure 2, argues for the parsimony of passive processes for primacy and recency effects. Experiments in the next section tested the auditory memory of rhesus monkeys in order to study related processes in another modality.

\section{AUDITORY MEMORY PROCESSING}

One question raised by the results shown in Figure 2 is whether the general form and changes of these func- tions with retention interval are characteristic of memory generally or are particular to visual memory. Would audi. tory memory, for example, show changes with retentior interval similar to those shown for visual memory? Woulc a modality effect, an auditory recency advantage showr. for humans, be shown for monkeys? If so, would it show up as a slower dissipation of the recency effect--that is. as a time course difference? To address these questions. we set out to test the auditory memory of rhesus monkeys.

We wanted to test rhesus monkeys in an auditory list memory task that was functionally equivalent to the visual list memory task previously described. But devising an adequate auditory list memory task proved challenging. After several unsuccessful attempts with other procedures, two rhesus monkeys, B.W. and F.D., learned the procedure shown in Figure 6 (Wright, Shyan, \& Jitsumori, 1990). These were the 2 subjects in the auditory memory experiments of this article.

Salient features of the task included a modified primate cage for testing. Three bars were removed so that the monkeys could touch copper screens in front of three speakers, as is diagramed in Figure 6. Touching the sound sources proved critical to learning the task (cf. Harrison, Iversen, \& Pratt, 1977).

List sounds were played from the center speaker for a 3-sec duration, with a 1-sec interval between them. A test sound was then played simultaneously from both side speakers for a minimum of 2 and a maximum of $6 \mathrm{sec}$. The same sound always came from both side speakers; never were different sounds played from the two side speakers at the same time. Responses were accepted after $2 \mathrm{sec}$ of test, and the choice response terminated the test sound. If the test sound matched one of the list sounds (same), a touch to the right-side speaker produced $3.5 \mathrm{cc}$ of Tang orange drink. If the test sound matched none of the list sounds (different), a touch to the left-side speaker produced a similar reward. Juice rewards were dispensed adjacent to each side speaker. Incorrect choices or aborts (not responding within the 2- to 6-sec response interval) were not rewarded and were followed by 30 -sec timeouts. Daily sessions were typically 32 trials in length, 16 same trials and 16 different trials.

Natural/environmental sounds from disc jockey sound effects records (Elektra Records, New York) were used in these studies (e.g., Morse code, stagecoach yells, dog howling, footsteps, seagulls, tea kettle, angry cat, riveting, crickets chirping, dentist drill, sheep baa, steamboat whistle, dinner triangle, carpet sweeper, children playing, water pouring, cable car clanging, woman laughs, horse whinny, air raid gliss, wood chopping, pig grunts, bell buoy, turkey gobbles, cuckoo clock, water well pump, frog calls, etc.). By using a large pool of 520 different sounds and shuffling them daily, interference from previous trials and associations among particular stimuli were minimized.

After learning the same/different concept with one list item (Wright, Shyan, \& Jitsumori, 1990), length of the list was gradually expanded (Wright \& Rivera, 1997). Serial position functions for lists of 6,8 , and 10 sounds 
CHAINING GROUP
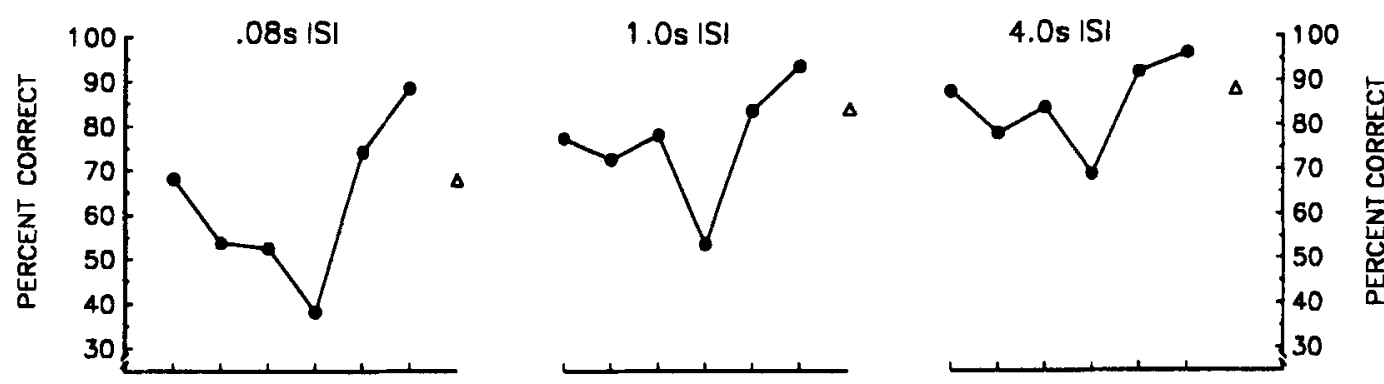

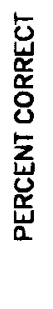
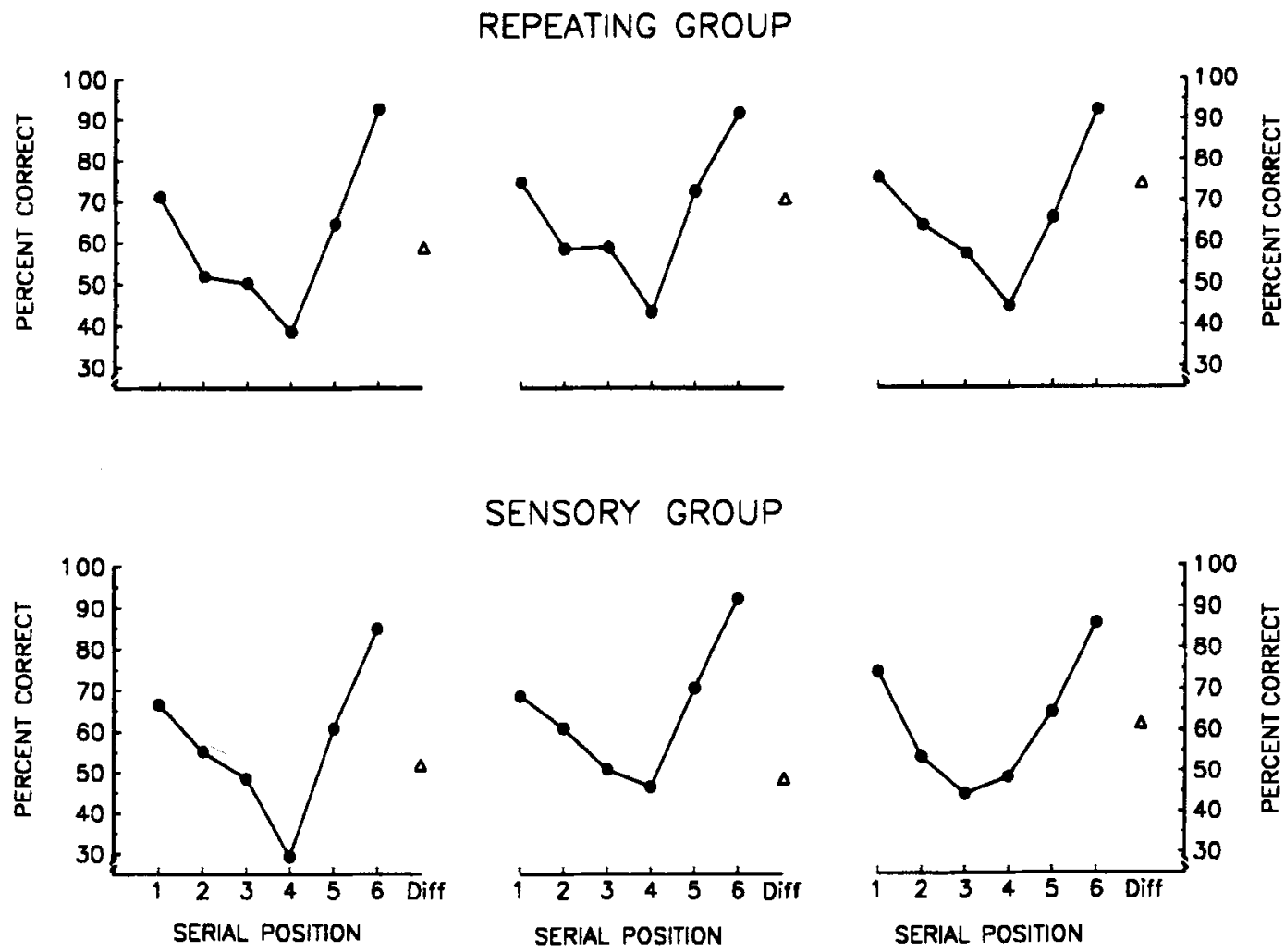

Figure 5. Serial position functions for humans according to the different interstimulus intervals and rehearsal strategies of Figure 4. Serial Position 1 was the first list item. Unfilled points (Diff) are performances on trials in which the test matched no list item. (After Wright, Cook, et al., 1990.)

are shown in Figure 7. These lists were tested under two different conditions. In one condition, the monkeys initiated lists (touching the center speaker), and the intertrial interval (ITI) was $12 \mathrm{sec}$. In the other condition, lists were not initiated by the monkeys, and the ITI varied from 12 to $27 \mathrm{sec}$. The results were similar from both conditions and the average is shown in Figure 7 . These serial position functions are $\mathrm{U}$-shaped and show primacy as well as recency effects.

The monkeys' auditory list memory was then tested at different retention intervals. The results were so surpris- ing that a series of replications and retests was conducted, including comparisons of 0.5 - versus $1-\mathrm{sec}$ ISIs, novel versus familiar stimuli, initiation versus no initiation of lists, fixed versus variable ITIs, and six versus four retention intervals. The results from all of these experiments were similar in terms of the general trends of the serial position functions (see Wright, 1998).

The results from one of these experiments is shown at the top of Figure 8 . The number and values of the retention intervals were the same as those tested in the visual retention interval experiment with rhesus monkeys, 

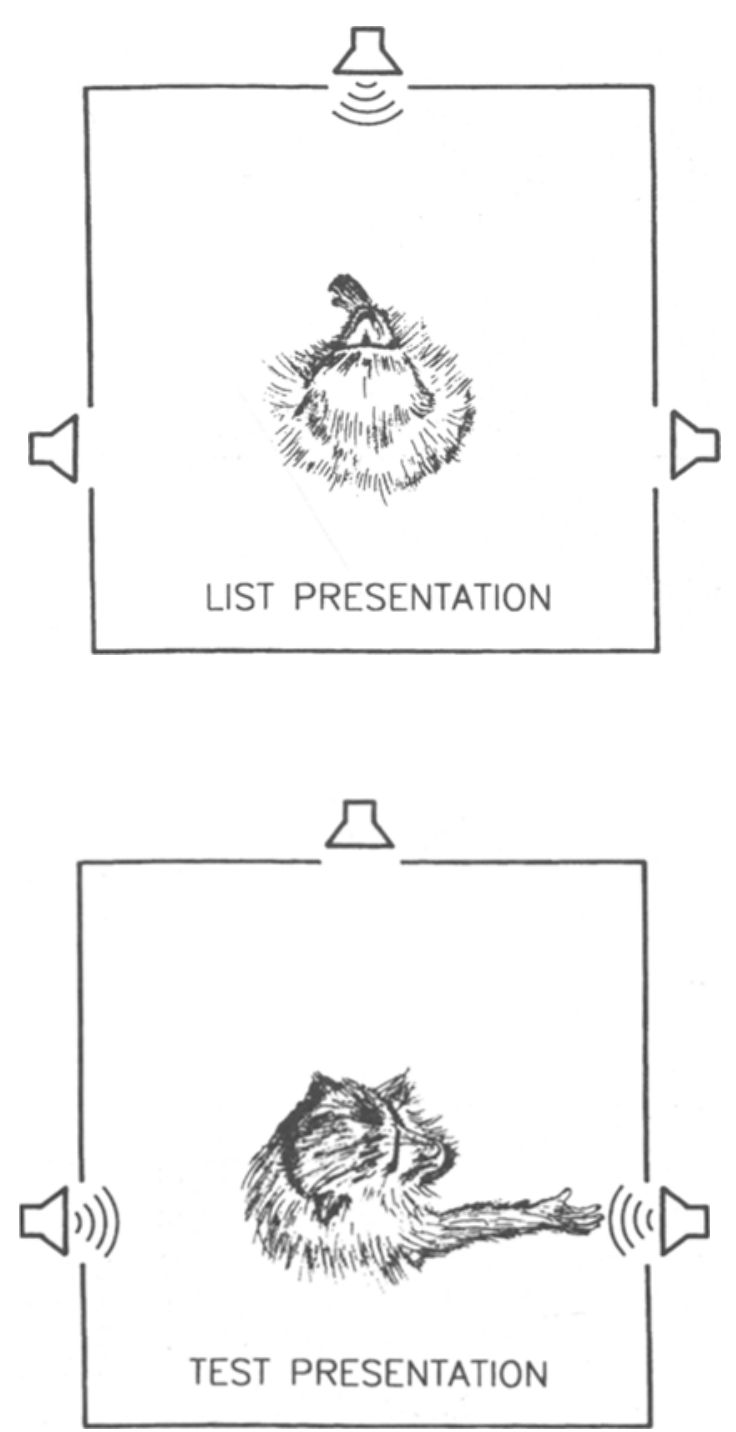

Figure 6. Schematic of the auditory testing procedure. Upper panel shows top view of a monkey with list sounds being presented from a center speaker. Lower panel shows top view of a monkey touching a right-side speaker with a test sound being presented from both side speakers. A touch to the right-side speaker was correct when the test sound matched a list sound, and to the left when it matched no list sound. (After Wright, 1998.)

shown in Figure 2. Five randomized 32-trial blocks of the six retention intervals were tested. This resulted in 20 tests for each serial position for each delay. The ITI varied from 12 to $27 \mathrm{sec}$, and trials were begun without center speaker initiating responses. List sounds were played from the center speaker for a $2-\mathrm{sec}$ duration, with a 1-sec interval between them. A test sound was then played simultaneously from both side speakers for a minimum of 2 and a maximum of $6 \mathrm{sec}$. The visual recognition memory results from Figure 2 for the rhesus monkeys are reproduced in Figure 8 to facilitate comparison.

Figure 8 shows that the auditory serial position functions are virtually opposite in shape to the visual serial position functions at many of the retention intervals. Auditory memory initially shows a primacy effect but no recency effect. Visual memory shows a recency effect but no primacy effect. At a 2-sec delay, the functions from both modalities are U-shaped. If memory had been tested only at the $2-\mathrm{sec}$ retention, one would probably conclude that auditory and visual memory were similar. For longer retention intervals, the functions diverge once again. Auditory memory then shows a strong recency effect and no primacy effect, whereas visual memory shows a strong primacy effect, and no recency effect.

\section{SOME IMPLICATIONS FROM THE AUDITORY AND VISUAL MEMORY RESULTS}

These dynamically changing serial position functions are not typical of serial position functions obtained from humans. One reason is that list lengths used to test humans typically are longer than those used in these studies. One benefit of longer list lengths is that they reduce the possibility of ceiling effects. But some of the serial position function changes that occur early in the retention interval with short lists may be unobservable with longer lists. Changes in the visual primacy effect, for example, may have run their course before a longer list has even finished being presented. Such early visual primacy effect changes have been shown for humans by using difficultto-code items, so that short lists can be used without encountering ceiling effects (e.g., kaleidoscope patterns, Wright et al., 1985; snowflake patterns, Neath, 1993b; and antique car drawings, Korsnes, 1995). Similar changes

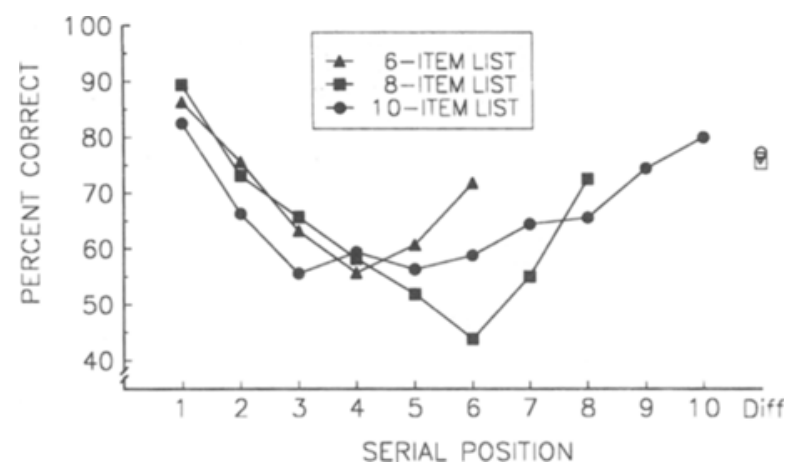

Figure 7. Serial position functions for the average (mean) memory performance of 2 rhesus monkeys with lists of 6,8 , or 10 environmental/natural sounds, each presented for 3 sec with a 1 -sec interval between sounds. Unfilled points (Diff) are performances on trials in which the test matched no list item. (After Wright \& Rivera, 1997.) 

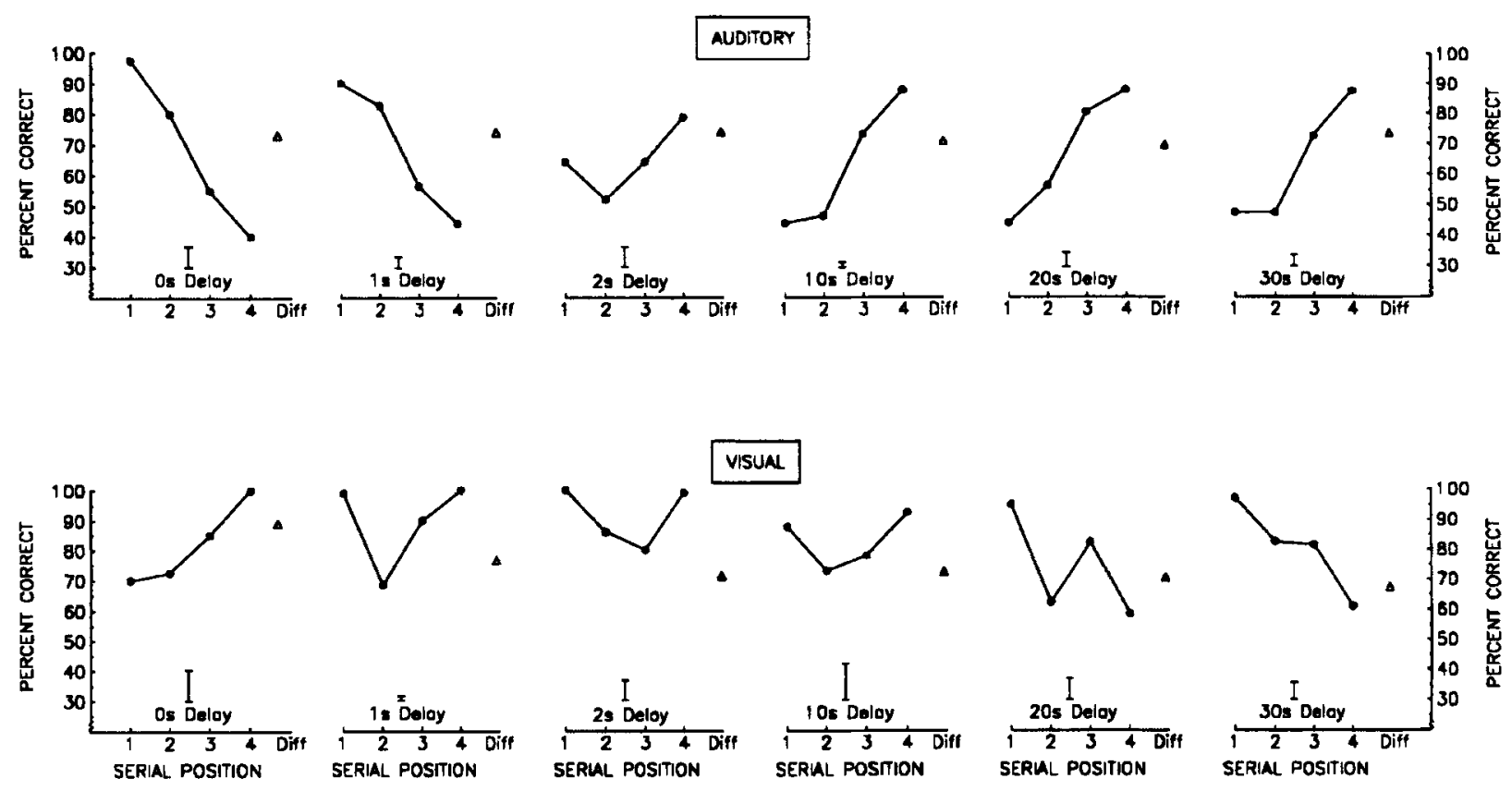

Figure 8. Upper panels: Mean auditory serial position functions for 2 monkeys in cases where the test sound matched one of the list sounds. Lower panels: Mean visual serial position functions for 2 rhesus monkeys from Figure 2. Serial Position 1 is the first item in the list. The parameter delay is the retention interval between list and test. Unfilled points (Diff) are from trials in which the test matched no list item. Error bars are the average standard error of the mean for the four serial positions of each function. (After Wright, 1998.)

may occur in the serial position effects with longer lists, but they cannot be observed under those conditions.

Another reason that these dynamically changing serial position functions are not typical of serial position functions obtained from humans may be differences in testing procedures. Recall procedures, typically used with humans, do not allow adequate control of retention interval for studying the range of retention interval effects, particularly the shorter retention interval effects. In the case of the visual primacy effect, humans required to recall all items they can remember (in any order) could first recall the last list items (because initially these are best remembered), thereby build a little delay, and then have less trouble recalling the first list items.

Although there is some evidence from humans for similar dynamically changing serial position functions for visual memory, I know of none that is comparable for human auditory memory. One reason may be that auditory memory is more difficult to test adequately than visual memory. A difficulty endemic to auditory stimuli is that they unfold in time rather than in space, as do visual stimuli. A longer time provides an opportunity for the subject to code the stimulus, or features (fragments) of it, into both visual and auditory memory codes. Cross-modality coding may contaminate memory studies. Memory deficits at a particular serial position in one modality may be offset by good memory at that same serial position in another modality.
There is, however, the well-known modality effect in human memory that is a recency advantage for auditory over visual memory (see, e.g., Greene, 1992, for a review). Somewhat reminiscent of the human modality effect is the trend in Figure 8 toward a strengthening of auditory recency effects and a weakening of visual recency effects with retention interval. Perhaps a similar trend difference in human serial position functions might play some role in the modality effect, in addition to possible feature processing (see, e.g., Nairne, 1990), temporal distinctiveness (see, e.g., Glenberg \& Swanson, 1986), or language (see, e.g., Shand \& Klima, 1981).

Madigan and McCabe (1971) presented lists of words auditorially. Lists were five pairs, with the first word of each pair serving as the cue for (recall of) the second. Tests were written (visual) presentations of the cue words. They showed that the serial position functions from an immediate test changed on a delayed test. The strong recency effect on the immediate test dissipated, leaving a primacy effect on the delayed test. This, of course, is similar to the pattern of changes shown for visual recognition memory. But it is difficult to compare this experiment with the experiments of the present article. Madigan and $\mathrm{McC}$ abe were exploring the negative recency effect (cf. Craik, 1970). Madigan and McCabe presented (and tested) 50 lists before giving subjects a surprise retest on all 50 lists. Although the delayed test did show a downward-sloping, primacy-dominated ser- 
ial position function, performance with the first list items did not improve (in absolute terms) relative to the immediate test. Thus, the results could be accounted for as a dissipation of the recency effect.

The monkey memory results that have been presented in this article, I believe, impose some limitations on models or theories of memory that might account for them. Although one could debate the generality of recognition memory with monkeys and with these stimuli, general theories of recognition memory should be able to account for these results.

Beginning with the auditory memory results, the strong initial primacy effect and absence of a recency effect for auditory memory raises difficulties for traditional interpretations that the recency effect represents STM. STM is, virtually by definition, memory that fades with time. But apparently not all STM works this way. The recency effect cannot represent rhesus monkey's short-term auditory memory, because a recency effect is not present initially. Its later appearance makes it more akin to characteristics associated with LTM.

The primacy effect is often associated with LTM (see, e.g., Atkinson \& Shiffrin, 1968; Glanzer, 1972; Waugh \& Norman, 1965). A primacy effect, however, is not present at the longer auditory retention intervals where LTM would be expected. By contrast, an auditory primacy effect is present initially where STM would be expected. And furthermore, similar to what would be expected of STM, the auditory primacy effect dissipates with retention interval.

Both visual and auditory memory show primacy and recency gradually changing over time. They each have a "limb" (auditory recency, visual primacy) that actually increases in terms of absolute recognition memory over time. This result is counterintuitive. Memory typically is thought to fade with time, not improve. Hypothetical processes of decay, unlearning, displacement, and interference have been proposed to account for the fading of memory. These improving memories occur before the other limb (auditory primacy, visual recency) fades with time. This is appropriate to prevent "holes" in memory. And, of course, this is the only way that traditional Ushaped serial position functions can be produced.

These results, taken together with those from primacy/ recency dissociation experiments, seem to implicate two passive memory processes with different time courses. Some memory processes with these characteristics are discussed in the following sections.

\section{MEMORY PROCESSES AND INTERFERENCE}

The purpose of the experiments in this section was to explore parameters that might alter the form of these functions and to begin to reveal something about the nature of the underlying memory processes. The choice of manipulations is, of course, tied to hypotheses about how recognition memory works. The following criteria figured into my choice of manipulations. (1) The processes should be passive, in the sense of not being based on an active strategy employed by the subject to enhance memory. (2) There should be two processes, to account for the different changes in primacy and recency effects. (3) The two processes should have differing time courses, to account for the separate time courses of primacy and recency. (4) The processes should be amenable to experimental manipulation. (5) Finally, such processes should have a demonstrated powerful influence on (the monkey's) list memory. Among processes that fulfill these criteria are those of interference.

\section{Interference Across Lists in Visual List Memory}

The purpose of the experiments summarized in this section was to evaluate and demonstrate the influence of interference on the monkey's list memory (criterion 5, above).

Before we conducted our visual memory experiments with monkeys, we thought the difficulty others had in obtaining good list memory performance from their monkeys was due to the abstract geometrical shapes and colors of the stimuli that they had used (see, e.g., Devine \& Jones, 1975; Eddy, 1973; D. Gaffan, 1977). Therefore, some of the pictures we used were of familiar objects (e.g., apples, animal caretaker, etc.) that might be better remembered. The experiment lasted several months $(16,000$ trials), and the 211 pictures were rank ordered according to memory accuracy. Pictures of familiar items, however, were not those best remembered. A somewhat unique feature of our experiment was a much larger set of memory items than those other researchers had used. D. Gaffan (1977, Experiment 1, phase 8), for example, used only 6 items (colors). The resulting accuracy with 3 -item lists was only $70 \%$ correct, whereas we had obtained $86 \%$ accuracy with a longer and more difficult 10 -item list. We considered that the small pool of items of the D. Gaffan (1977) experiment may have led to greater interference than did our larger pool of items and, thus, might have been responsible for the poorer performance.

To test this interference possibility of pool size, we tested performance with 3 -item lists under two conditions (Sands \& Wright, 1980a). In the high-interference condition, 3-item lists were composed from a pool of 6 items, similar to the D. Gaffan (1977) experiment. In the low-interference condition, 3 -item lists were composed from a 211 -item pool. Conditions alternated with daily sessions. Recognition performance was $70 \%$ in the highinterference condition, virtually identical to that of the D. Gaffan (1977) experiment. Recognition performance was $96 \%$ in the low-interference condition. Thus, interference from item repetitions lowered performance by $26 \%$.

The locus of this repeated-item interference was shown to be test items on different trials in which the test did not match any list item. Having seen the test item, perhaps 
even in the previous trial, confuses the subject; it tends to think that the item occurred in the list being tested. In the locus-of-interference experiment, interfering items were systematically placed in previous lists (Wright, Urcuioli, \& Sands, 1986). The separation between the interfering item and its reappearance as a test on a later different trial was manipulated. When the interfering item was in the immediately preceding list, performance was $64 \%$. As separation increased, performance improved. When the separation was five lists, or 60 items, performance was $83 \%$. But still, this $83 \%$ was $10 \%$ less than the $93 \%$ correct from an interference-absent condition.

In an experiment on long-term interference, Jitsumori, Wright, and Cook (1988) showed that interference could assert its effects across days or even weeks. Monkeys performed in a 4-item list memory task, with lists composed from a 320 -item pool. Items were seen only once daily, and thus, from the standpoint of individual sessions, this should be a low-interference condition. Items and sequences were rearranged daily. The monkeys had been tested with the same 320 items for several months. Over this period, memory performance gradually deteriorated. Following a variety of unsuccessful attempts to remedy this deteriorating performance (e.g., by changing the type of juice reinforcer), tests with novel items resulted in a rise in memory performance from $63 \%$ to $82 \%$. Other tests confirmed that this was interference from seeing the items in previous sessions, and the locus of this interference was the same as that in the previous study - test items on different trials.

\section{The Possibility of Interference Within Memory Lists}

The previous section presented evidence of the disruptive effects of interference from items that were repeated from previous lists. In this section, interference from items within individual lists is considered in terms of their possible effect on the primacy and recency effects of the serial position function.

Interference has a considerable history in its relation to the serial position function. Interference was hypothesized to produce the $U$-shape of the serial position function by a convergence of proactive interference (PI) and retroactive interference ( $\mathrm{RI}$ ) on the middle items of the list (Foucault, 1928; Hull, 1935). Previous items interfere (proactively) with memory of later items, and later items interfere (retroactively) with memory of earlier items. List memory was thought to be a stimulus-response chain in which the previous response(s) were the stimuli for the next response. This line of reasoning was further extended by the interference theory of forgetting (see Crowder, 1976). Interference theory sought to reduce the more complicated serial position function to a stimulusresponse unit. Thus, subjects learned paired-associate lists. Although a discussion of interference theory is beyond the scope of this article, it can be said that by learning two paired-associate lists with the same stimulus items, the effects of interference could be assessed in relation to a control group. RI was produced by second-list learning interfering with first-list responses. PI was produced by first-list learning interfering with second-list responses.

Among the findings from interference theory research was that the effects of PI and RI had different time courses. The effects of PI were weak immediately but slowly strengthened over time (see, e.g., Keppel \& Underwood, 1962; Postman, Stark, \& Fraser, 1968). The effects of RI were strong immediately, but dissipated comparatively rapidly (see, e.g., Briggs, 1954; Postman et al., 1968; Postman, Stark, \& Henschel, 1969; Underwood, 1948a, $1948 \mathrm{~b})$. These time course differences seemed to hold over time scales ranging from minutes to days. Within the rubric of interference theory, PI and RI were considered experimental manipulations, and the (hypothetical) processes by which they affected memory were thought to be response competition and unlearning. Use of the terms PI and RI in this article does not imply any reference to response competition or unlearning. Interference is itself considered to be the process that affects recognition memory.

Whether or not time courses for (the effects of) PI and $\mathrm{RI}$, similar to those revealed through interference theory research, apply to the monkey's visual list memory is an open question. But several arguments can be made for such a possibility. In addition to the attributes of two (independent) processes and two different time courses, interference is a passive process that would be expected to apply to animals as well as to humans. Even in those human visual memory tasks in which similar changes in primacy and recency have been shown (e.g., those using kaleidoscope or snowflake patterns), passive memory processes would be expected to prevail. These different time courses for PI and RI could conceivably account for the primacy and recency changes shown for visual recognition memory. An initial strong RI could mean that the last list items would interfere with memory of the first items. Initial weak PI would result in a serial position function with a strong recency effect and no primacy effect, similar to the results obtained. Dissipation of RI would allow the primacy effect to appear, thereby producing the U-shaped serial position function. As PI strengthens and RI dissipates, the primacy effect should strengthen, and the recency effect should weaken. These were the trends shown in the serial position functions in Figure 2.

\section{Tests for Interference Within Auditory Lists}

Similar time course arguments could be made for auditory memory. But if PI and RI time course differences were to play a role in the shape of the auditory serial position functions, the roles of PI and RI would need to be exchanged. That is, PI would have to be strong initially and dissipate with time, whereas RI would have to be weak initially and strengthen with time. I know of no auditory experiments assessing RI and PI time course differences. Even if there were such experiments using verbal stimuli (e.g., words), there would be no guarantee that they would be relegated exclusively to auditory memory. 

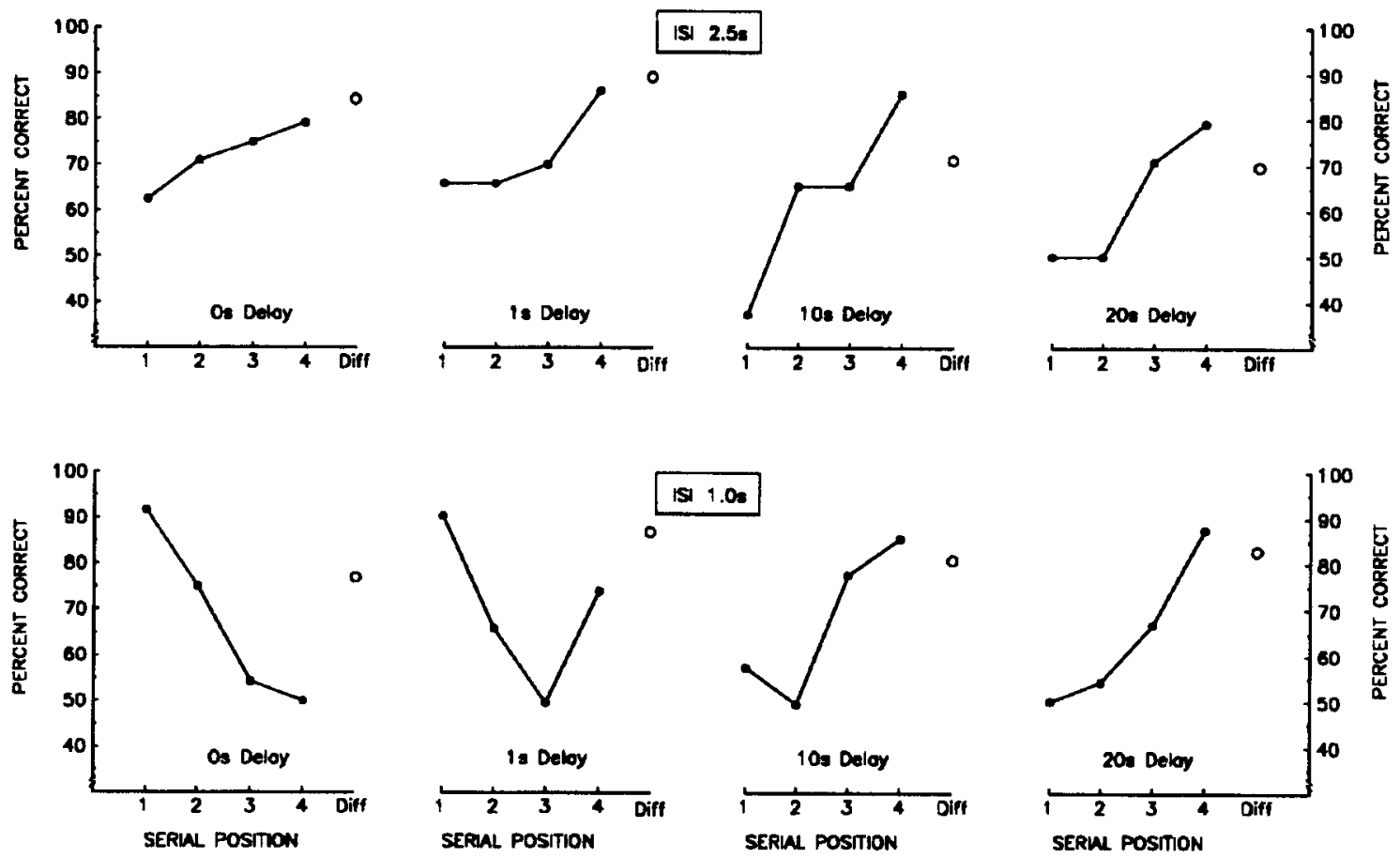

Figure 9. Mean serial position functions for two monkeys tested with a 2.5-sec interstimulus interval (upper panels) and compared with results from a similar experiment (lower panels) but in which the interstimulus interval was 1 sec. Unfilled points (Diff) are performances on trials in which the test matched no list item. Delay is the retention interval between list and test. (After Wright, 1998, in press-a.)

Auditory stimuli are often visualized in the mind's eye of the subject (see, e.g., Campbell \& Dodd, 1980).

With these considerations, several experiments were conducted to explore the possibility that interference plays a role in determining the shape of the monkey's auditory serial position function. If items in the list were interfering with one another, one way to test for this possibility would be to separate list items and, thereby, reduce any interference. On the immediate $(0$-sec) auditory test (Figure 8), for example, the first list items might (proactively) interfere with the monkey's memory of the last list items. Increasing the separation between items might diminish this PI and, thereby, allow recognition on the last list items to improve.

The procedure was similar to the retention interval auditory experiment shown in Figure 8, except that the ISI was $2.5 \mathrm{sec}$ and only four retention intervals $(0 \mathrm{sec}, 1 \mathrm{sec}$, $10 \mathrm{sec}$, and $20 \mathrm{sec}$ ) were tested. As before, retention delay varied daily in three randomized blocks of the four delays. The results are presented in Figure 9, together with the results from an otherwise identical experiment in which the same retention intervals were tested with a 1 -sec ISI.

Clearly, the greatest effect was at (short) retention delays of 0 and $1 \mathrm{sec}$. One aspect of this ISI change that deserves special attention is the extension of time between individual list items and the test item. Time extension was greatest for the first list item and proportionally less for each successive item. Consider the 0 -sec delay results. Performance for the first list item in the 2.5 -sec ISI test was $62.5 \%$ correct, as compared with $91.7 \%$ correct in the $1-\mathrm{sec}$ ISI test. The added time to test for this first list item was $4.5 \mathrm{sec}$. Although this is less than the $10 \mathrm{sec}$ added by the 10 -sec retention interval, a comparison might provide clues about trends in these performances. First item performance with the 10 -sec delay, $1-\mathrm{sec}$ ISI test is $58.3 \%$ correct, roughly similar to the $62.5 \%$ in the 0 -sec delay, 2.5 -sec ISI test. Interesting is the increase in performance for the last list item in the 0 -sec delay, 2.5sec ISI test relative to this same delay in the 1 -sec ISI test. There was no difference in time to test for this last list item, because no ISI followed it. Nevertheless, performance increased from $50 \%$ to $79.2 \%$ correct. This performance increase must be the result of changes coming before this item. Such a result implicates a change in PI from the first list items on recognition memory for the last list items.

In the 2.5-sec ISI experiment, recognition of the first items may have been altered as a function of total time to test. The PI from the first list items on recognition of the last list items may, in turn, have been altered relative to the $1-\mathrm{sec}$ ISI condition. To more accurately test this possibility, only the middle ISI was altered (Wright, in press-a). The middle ISI was increased to $3 \mathrm{sec}$, whereas the other two ISIs remained at $1 \mathrm{sec}$. Thus, the time to test for the first and second items was extended by $2 \mathrm{sec}$, 


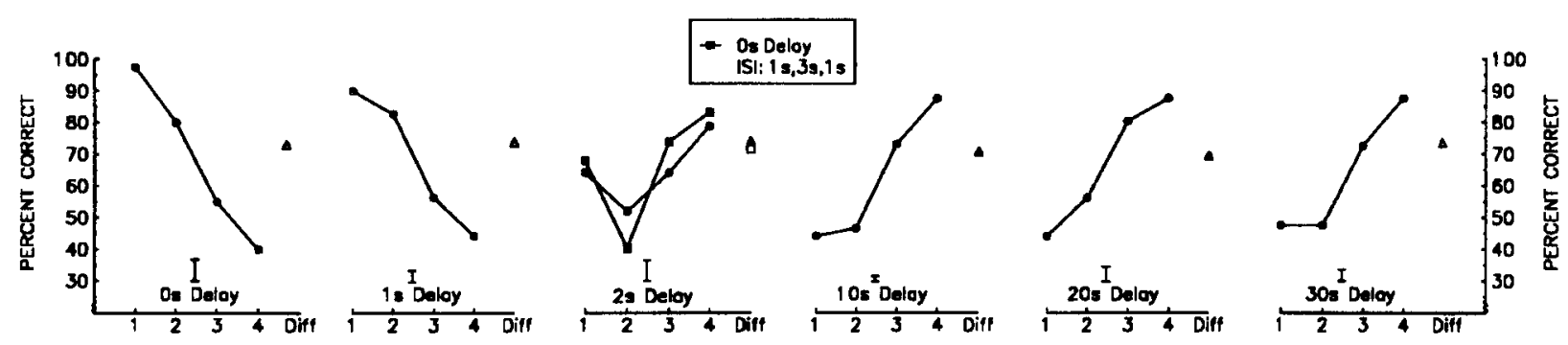

Figure 10. Mean results from a 0-sec delay test with the middle interstimulus interval (between the second and third list items) extended from 1 to $3 \mathrm{sec}$. This serial position function is superimposed on the 2 -sec retention delay function from Figure 8, making the time to test the same for the first two list items. Unfilled points (Diff) are performances on trials in which the test matched no list item. (After Wright, in press-a.)

whereas the time to test for the third and fourth items remained unchanged relative to the $1-\mathrm{sec}$ ISI condition. Memory performance for the first two items could then be compared with performance for the first two items of the 2-sec delay function of Figure 8, because time to test for the first two items would be the same. For the last two list items, the time to test was unchanged so that their memory could be compared with the 0 -sec delay function of Figure 8. Other aspects of the procedure were unchanged.

Because the focus of the experiment was on the $0-\mathrm{sec}$ delay function, the results from the 0 -sec delay condition are superimposed (squares) on the 2-sec delay function from Figure 8 and are shown in Figure 10. Adding $2 \mathrm{sec}$ to the ISI (between second and third items) seems roughly to substitute for $2 \mathrm{sec}$ of retention delay (in the 1 -sec ISI condition) in determining performance for the first two list items. Also of interest is the change in recognition performance for the last two items in the test condition. Retention delay for these last two list items was unchanged (relative to the $0-\mathrm{sec}$ delay, 1 -sec ISI condition), but performance improved and was not too dissimilar from the 2-sec delay, $1-\mathrm{sec}$ ISI condition. Since retention delay for these last two items was unchanged by the insertion of a $3-\mathrm{sec}$ ISI in the middle of the list, these results show that performance on the last two list items was determined largely by performance of the first two list items. Such a result implicates a change in PI of the first items on recognition memory of the last two items. Delay itself certainly does not directly affect recognition of last list items. Extending the overall time to test for the first two items reduces memory of the first two items and appears to reduce interference from these first two list items on recognition memory of the last list items.

\section{Manipulating Background Proactive Interference}

These ISI manipulations implicated PI as being instrumental in affecting the recognition performance for the last list items. Other converging operations were sought in the experiments presented in this section, converging operations that would leave time to test constant but would be expected to affect PI. In the previously presented auditory experiments, PI from previous trials had been minimized. Items in any one trial were unique on a daily basis, and the items varied somewhat from day to day as they were selected from a 520 -item pool. Minimizing interference from previous lists allowed monkeys to perform the task accurately and may have been instrumental in their being able to learn the task in the first place. This across-list PI, as it will be called, was manipulated in the experiment described in this section. If within-list PI, as described in the ISI experiments of the previous section, were somehow vulnerable to across-list PI, then last-item performance might even improve under the higher (across-list) interference conditions.

Across-list PI was increased by decreasing the item pool and, thereby, increasing repetitions of list items within a session (Wright, in press-a). The item pool was gradually decreased from 144 items (trial-unique/session) to 8 items. Each of the 8 items was repeated in 16 lists tested daily. The same 8 items were used throughout the experiment. As is shown in Figure 11, repeating items in the 8 -item condition lowered overall performance relative to the 144-item condition. Of particular interest was the change in the form of the serial position function at the 0 -sec retention delay. This function changed from a primacy-dominated, downward-sloping function to a recency-dominated, upward-sloping function. The 20-sec delay function, by contrast, was largely unchanged in its form by item repetition, despite its somewhat lower overall level.

The across-list PI had a detrimental effect on the first two list items of the 0 -sec delay function. Recognition of the first two items changed from $92 \%$ and $96 \%$ to $54 \%$ and $50 \%$, respectively. Recognition of the last list item showed an equally dramatic change in the opposite direction. Performance rose from $46 \%$ to $83 \%$ correct.

There is no a priori reason that I can think of as to why the first list items should be the target of interference from item repetition any more than the last list items. But they seem to be. The lowering of first-item performance diminished their (within-list) PI effect on last-item recognition. This latter finding may not be entirely surprising, considering that items need to be remembered in order to interfere with other memory. In any case, these two forms of PI may be different in nature. Under conditions of across-list PI, the subject recognizes the item but has trouble remembering in which list it was presented (cf. 

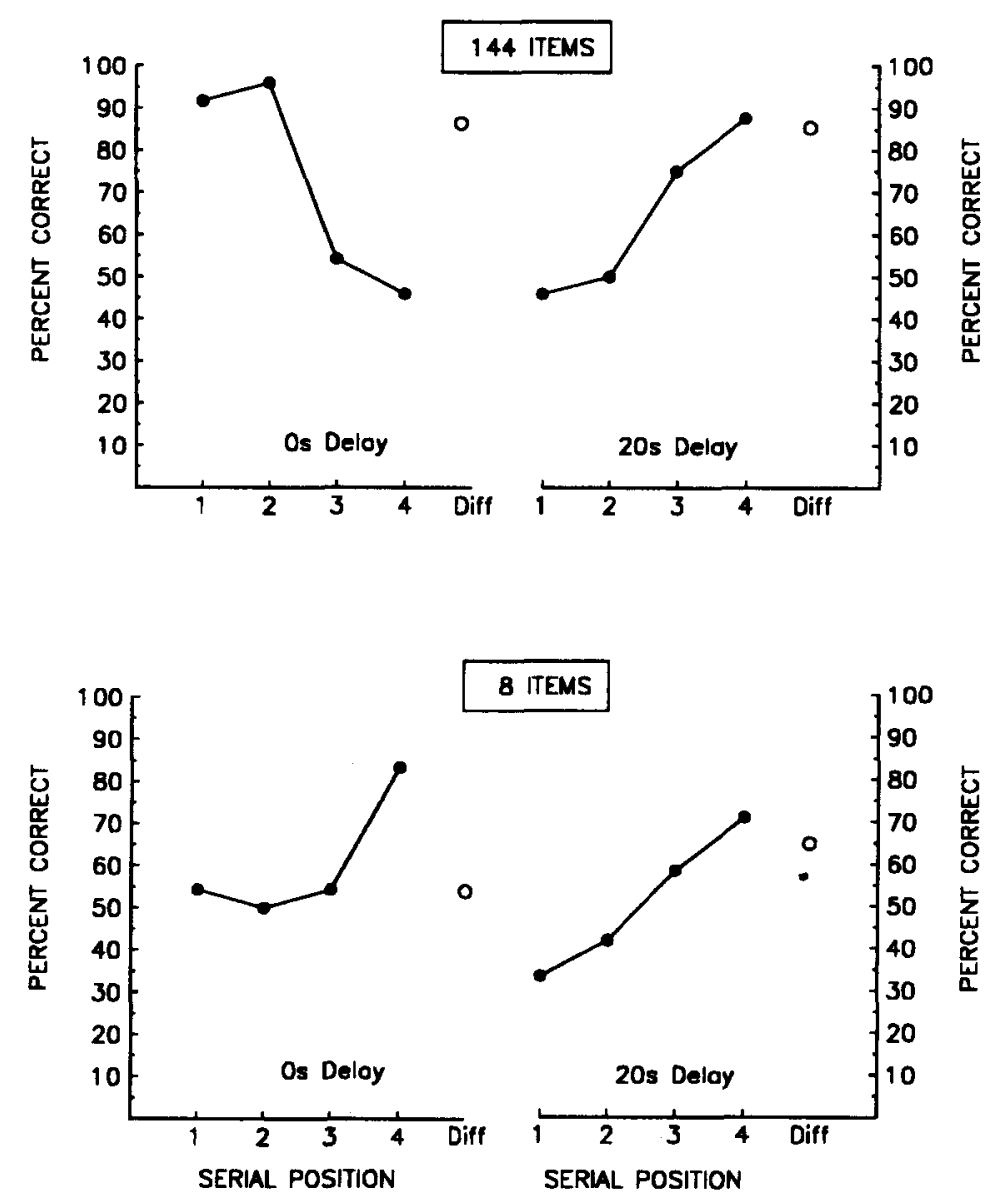

Figure 11. Mean serial position functions for 2 monkeys tested at 0 - and 20-sec retention delays, with sounds unique to each trial (upper panels) or with sounds repeated in 16 different trials (lower panels). Unfilled points (Diff) are performances on trials in which the test matched no list item. (After Wright, in press -a.)

Glenberg, 1987; Gorfein, 1987). Under conditions of within-list PI, it seems that the subject does not recognize the item. Within-list PI occurs across diverse items and dissipates in about $2 \mathrm{sec}$ (in this task). Across-list PI occurs across similar items (repetitions, primarily) and persists for minutes, days, and even weeks.

This finding that across-list PI can effectively remove within-list PI means that the changes in auditory recognition memory shown here for short retention delays need to be studied under conditions of minimal PI from previous lists. Perhaps this is easier to do with monkeys than with humans. For example, the use of digits in human memory testing results in PI because the nine digits are frequently repeated within and outside the experimental setting. In addition, humans tend to chunk digits and visualize them, creating a visual code. If the serial position functions for auditory and visual memory are of opposite shape, visualizing auditorially presented items or vice versa will help recognition but make it difficult to separate the visual and auditory contributions to overall performance.

\section{Interference and Category Separation}

Increasing item repetitions increased interference across the whole list. But if the major effect of this interference is on the first list items, the same result should be obtained if the repeated-item PI effect were confined to only the first list items. In order to test this possibility, mixed lists were tested with either the first two items or the last two items from the high-PI condition (8-item set) and the other two from the low-PI condition (144-item set) (Wright, in press-a).

Figure 12 (lower left panel) shows that making the first two items from the high-PI set diminished the primacy effect and produced a strong recency effect. This shows that the main effect of PI at 0 -sec delay is on the first two items.

Results presented in the lower right-hand panel of Figure 12 show the effect of making the last two list items from the high-PI set. In this case, recognition performance on the last two items was diminished, and a primacy effect was produced. This result indicates that the poor recognition of the first two items in the 20 -sec delay baseline 
condition (upper right-hand panel) may have been due to $\mathrm{RI}$ from the last two items adversely affecting recognition of the first two items. The result of the last two list items being from the eight-item pool appears to be a case in which RI was altered. The eight items of the high-interference condition might function as a category, distinct from the larger pool of items. A category separation between the first and last list items should help prevent items at one end of the list from interfering with recognition of items at the other end of the list. We have obtained similar performance changes using natural categories (e.g., horns, bird calls, etc.) in place of the high-interference, eight-item "category." Items from a natural category did not diminish performance as severely as did the high-interference category. Still, when the first two items were from a natural category, performance improved on the last two items, showing a recency effect. The reverse occurred when the last two items were from a natural category.

\section{GENERAL DISCUSSION}

\section{Conclusions}

Conclusions and some implications from the monkey visual and auditory memory experiments can be summarized as follows.

The rhesus monkey's visual and auditory serial position functions are essentially of opposite shape at the shortest retention intervals. These functions change in opposite directions with increases in retention interval. For visual memory, the primacy effect grows and the recency effect dissipates with retention interval. For auditory memory, the recency effect grows and the primacy effect dissipates with retention interval (see Figure 8).

Changes in primacy and recency effects for visual and auditory memory implicate two memory processes with different time courses. Evidence indicates that these memory processes are passive rather than active (e.g., they are not rehearsal based). Thus, passive (nonwillful) processes are capable of producing primacy effects as well as recency effects.

Manipulations of the ISI in auditory memory indicated that the primacy effect varied as a function of total time to test, whereas the auditory recency effect did not vary with total time to test. Other evidence indicated that the auditory recency effect varied as a function of PI from the first list items.

The background of PI in auditory list memory was increased by decreasing the item pool size (from 144 items to 8 items), which required reusing items. The form of the auditory serial position function changed from a downward-sloping function dominated by a primacy effect to an upward-sloping function dominated by a recency effect. This across-list PI seemed to have its effect primarily on the first list items. The lowering of performance to the first list items diminished the within-list PI effect of the first list items on recognition of the last list items. Similar serial position function changes were shown by limiting across-list PI to only the first 2 list items and selecting the last 2 list items from the larger item pool set. A category separation between the first and last list items formed by the 8-item, high-PI set may also have enhanced this change in the form of the serial position function. When the last 2 list items were from the 8-item, high-PI set, the form of the serial position function changed from an upward-sloping function dominated by a recency effect to a downward-sloping function dominated by a primacy effect. Here, too, category separation may have diminished RI from the last 2 items on recognition of the first 2 items.

\section{An Interference Framework for the Results}

For a variety of reasons, a formal model or theory of these results would be premature. On the other hand, from the direction of the auditory interference experiments, it should be apparent that, in my opinion, an interplay between PI and RI processes, each with its own time course, plays a role in these dynamically changing serial position functions.

How these interference processes interact to produce these changing serial position functions is suggested by the following possibility. In visual recognition memory, RI from the last list items might initially interfere with the subject's memory for the first list items and, thereby, produce a recency-dominated function. As time passes, PI from the first list items might grow as RI wanes, producing a primacy-dominated function. The PI and RI time courses might be exchanged in auditory memory, as is indicated by the auditory interference experiments.

This is a pretty bare bones and simple framework. Some might say simplistic. In one sense, I would have to agree. I can imagine many things that will modify it. Background interference clearly modifies it. Add to this such things as rehearsal, levels of processing, and cross-modality coding (just to name a few), and the situation could change radically. Context changes, endpoint distinctiveness, and distractor activity will change it, too. Of what generality, then, is such a framework-or even the research itself?

I feel that its generality actually resides in its comparative simplicity of conditions. This is a same/different recognition procedure that is one of the simplest relational (working memory) procedures. Only one test item is presented after each list, which allows control of delay and avoids response-output interactions. A large number of memory items are used, which minimizes PI from previous trials. Monkeys can reasonably be assumed not to rehearse memory items in these tasks, which avoids the possible influence of such strategic processing or appeal to it as a hypothetical explanatory construct. Monkeys can also be assumed to be less likely than humans to cross-modality code the items, which avoids confounding effects on overall memory performance from multiple modalities. 


\section{Distinctiveness as an Alternative Framework for the Results}

A case can be made for distinctiveness to account for serial position effects similar to those shown in the present article (e.g., Murdock, 1960; Neath, 1993b). In some sense, poor recognition of an item must be the result of that item's not being distinctive (in memory). But what causes it not to be distinctive may be more fundamental. Although endpoints of the list can be pointed to as the cause of distinctiveness, they are likely to be instrumental in other memory processes as well. With regards to the possibility of different time courses for different interference processes, the interference processes must somehow be reset at the endpoints. For example, if RI is high immediately after learning, it will need to reset with new learning. A continuous memory test with no real starting or stopping point may be composed of underlying cycles of interference, but there may be no way of decomposing them. For similar reasons, some of the effects of interference may be less observable with long lists.

Other evidence, including dissociations of primacy and recency effects, would seem to favor two processes over one. It is difficult to imagine how some drug (e.g., alcohol, diazepam, atropine) could selectively make one or the other endpoint nondistinctive (see, e.g., Castro, 1995, 1997; Jones, 1973).

Another problem for distinctiveness is explaining what might make distinctiveness change with retention interval. In human memory studies, appeal can be made to a possible difference in perspective that might vary with retention interval (Crowder \& Neath, 1991). At short retention intervals, subjects might "view" their memory from the perspective of the end of the list, like a receding row of telephone poles. At longer retention intervals, they might take a perspective from the beginning of the list. Such strategies apparently can be effective in chang-
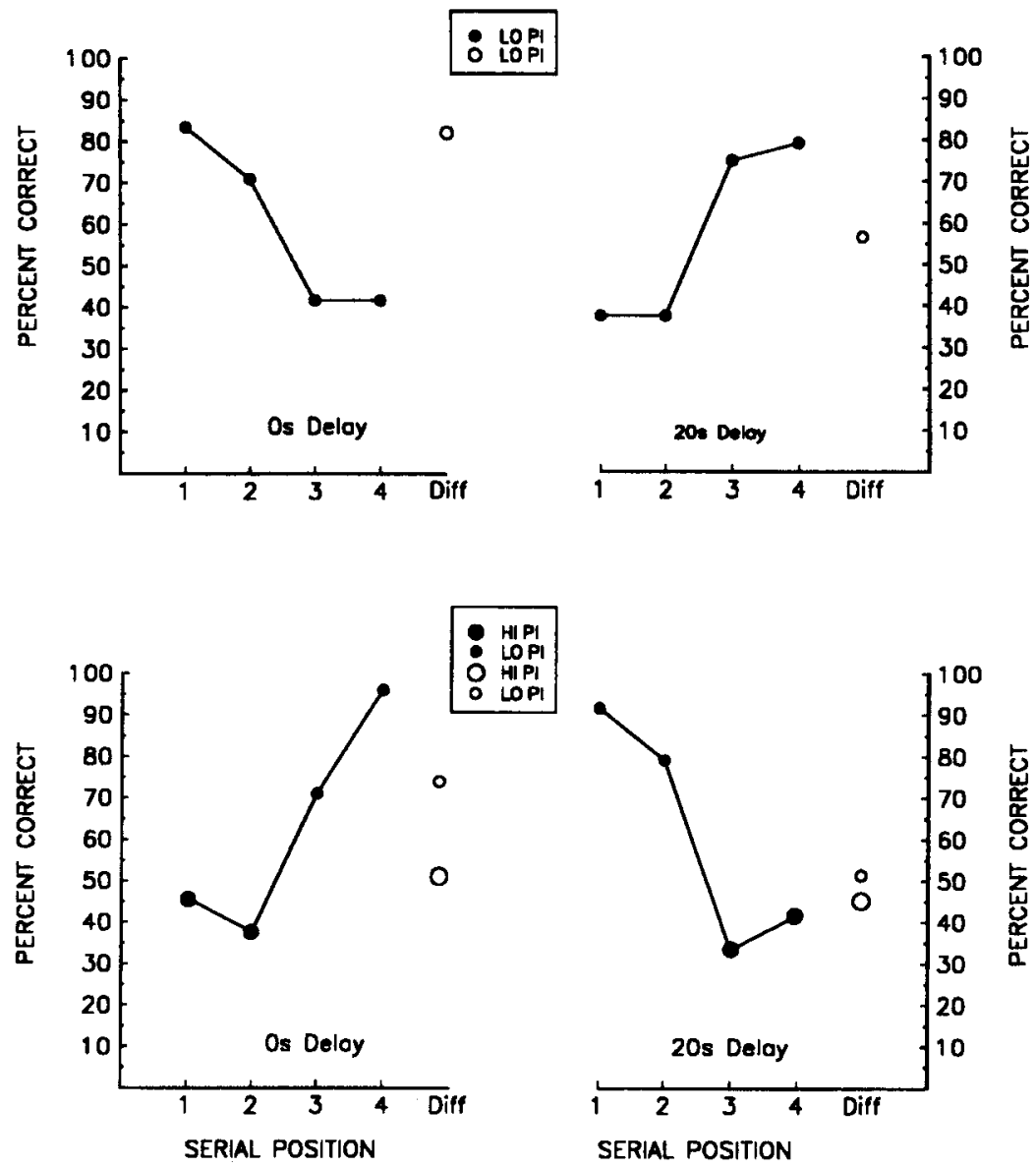

Figure 12. Upper panels: Mean serial position functions for $\mathbf{2}$ monkeys tested at $\mathbf{0 -}$ and 20-sec retention delays with trial-unique sounds and low proactive interference (LO PI). Lower panels: Mean serial position functions with either the first two list items or the last two list items from the eight-item, high proactive interference (HI PI) category of Figure 11 and the other two items from the LO PI set. Unfilled points (Diff) are for tests on which the test sound was different from all the list sounds. (After Wright, in press-a.) 
ing the shape of the serial position function (Crowder \& Neath, 1991). But it is unlikely that animals would adopt such strategies. Even less likely is the possibility that all of the animals whose results are shown in Figure 2 would adopt this same strategy.

Related to the issue of distinctiveness changes with retention interval is the question of the basis on which one would expect distinctiveness in auditory memory for monkeys to be essentially opposite to that in visual memory? If distinctiveness were the controlling variable, how would one account for the across-list interference results shown in Figure 11? On what basis would one expect across-list interference to diminish distinctiveness at the beginning of an auditory list and enhance it at the end of the list?

As a practical matter, distinctiveness is difficult to control, manipulate, and test. It is, therefore, difficult to substantiate its role or rule it out completely. I think a likely possibility is that combinations of different factors will be instrumental in serial position effects. I would not be surprised if the relative contribution of different factors varied in different situations and contexts. If so, the prognosis for any general account (theory) of serial position effects is not favorable.

\section{Other Proposed Explanations for (Some of) the Results}

It is not uncommon to speculate about alternative explanations for (some) results such as those presented in this article. These proposed explanations have varied as widely as their sources, which have included manuscript reviews and colleagues' comments. Since some of these possibilities will probably occur to other readers, they will be briefly discussed.

Consolidation. It has been suggested that the lack of a recency effect for the short-delay auditory serial position functions may be due to lack of memory consolidation for these items. That is, the immediate presentation of the test prevented memory consolidation. This possibility, I believe, can be discounted by results shown in Figure 12. In Figure 12 for the two $0-\mathrm{sec}$ delay tests, the last two items were the same (low PI, large item pool), and the test was the same. Thus, consolidation should be the same for the last list items. But there was a strong recency effect for the last two items when the first two items were from the high-PI set. Thus, the lack of a recency effect in the baseline condition (upper left-hand panel) probably does not involve consolidation.

Configural processing. It has been suggested that monkeys in the auditory task might be configuring the list as a gestalt whole instead of perceiving the list as made up of individual items or elements. I think it is unlikely that something perceived as a configural whole would show changes in memory for items at different serial positions with retention interval. Indeed, why would monkeys show memory for any individual item, let alone memory changes, if the list were really processed as a configural whole? In addition, if lists were perceived as a configural whole, elements from previous lists would not be expected to produce PI. But there was PI from elements of previous lists.

List continuation and suffix effects. It has been suggested that the lack of an auditory recency effect at the short retention intervals may have resulted from monkeys confusing the test sound as a continuation of the list. This possibility was anticipated when the experiment was designed. To reduce this possibility, test sounds were presented in different locations (side speakers) from the list sounds (center speaker). Also, the behavior of the monkeys would tend to discount such an explanation. Monkeys typically sat facing the center speaker when the list was being presented. When the test sound was presented, they turned to one side or the other (after $2 \mathrm{sec}$ of test sound) and made a touch response to a side speaker. Monkeys behaved in a similar manner whether the test followed immediately or after a long delay. If the test was confused as a continuation of the list, they should not have oriented toward a side speaker and made a side speaker response during the test presentation. But they did.

A related issue is the possibility of suffix-like effects from the immediate presentation of the test item. Suffix effects diminish recency effects in human auditory list memory (see, e.g., Greene, 1992). The suffix effect argument is somewhat different from the list continuation argument. The suffix effect is a memory effect, not a confusion regarding the end of a list. In this case, it is not possible to eliminate the probe item in order to test its role as a suffix item; the probe item is the only way to test recognition memory. But results from the interference tests shown in Figures 11 and 12 at the 0 -sec retention delay bear on this issue and the list continuation proposal. In one test condition (Figure 11, lower left-hand panel), all items were from the eight-item, high-PI set. In the other test condition (Figure 12, lower left-hand panel), the first two list items were from the high-PI set and the last two items were the same as those of the baseline conditions. In both test conditions, unlike the baseline conditions at this 0 -sec delay, strong recency effects were produced. By definition, the test followed the list items identically in all of these cases. So, if suffix-like effects or list continuation effects were instrumental in eliminating the recency effect in the baseline conditions (e.g., Figures 11 and 12, upper left-hand panels), they should also have eliminated recency effects in these test conditions. But they were not eliminated; strong recency effects were produced.

Blocked versus random delays. It has been suggested that improvement in visual recognition of early items (primacy effect) with retention interval may have been due to greater separation of lists at the longer delays. According to the argument, longer retention intervals would further separate lists and thereby reduce PI from previous lists. Evidence from several of the experiments would tend to discount such an explanation. Memory items were selected to minimize PI from previous lists. These conditions of minimal interference from pre- 
vious lists were just the conditions that produced robust changes in primacy and recency effects with retention interval (Figures 2 and 8 ). Other evidence comes from humans tested under blocked and random conditions. Neath (1993b) showed similar primacy and recency changes with retention interval under blocked and random conditions. In addition, I have tested monkeys in random as well as blocked conditions (unpublished). Although the results were somewhat more variable than those in blocked conditions, the primacy and recency changes with retention interval were similar. Since these are difficult tasks for monkeys, I have tended to choose conditions that produce performances that are as high and stable as possible.

Other evidence against such an explanation comes from ITI manipulations. If list separation were instrumental in producing the serial position function changes shown (e.g., Figure 2), serial position effects should change as a function of ITI. Two different ITIs $(5 \mathrm{sec}$, $10 \mathrm{sec}$ ) were tested with the capuchin monkeys whose data are shown in Figure 2. Their serial position effects and changes with retention interval were very similar from both conditions (Wright, in press-b). In addition, variable ITIs $(12-27 \mathrm{sec})$ were tested in the auditory memory task, and no systematic differences were found as a function of ITI (Wright, 1998; Wright \& Rivera, 1997). Thus, it seems unlikely that list separation, in itself, is responsible for producing the retention interval changes in primacy and recency effects for visual and auditory memory.

Response bias. In a recent article, Kerr, Ward, and Avons (1998) tested humans at two retention intervals $(0 \mathrm{sec}, 10 \mathrm{sec})$ in a four- alternative, forced-choice (4AFC) task. The distribution of choices varied somewhat for the two retention intervals. These differences for the four serial positions can be characterized as a difference score by subtracting the percent choices in the 0 -sec condition from those in the $10-\mathrm{sec}$ condition: $+12 \%, 0 \%,-4 \%$, $-8 \%$ with blocked retention delays and $+9 \%,-1 \%,+2 \%$, $-9 \%$ with randomized retention delays. Kerr et al. applied a correction for suspected guessing and concluded that response biases (response distribution differences) could account for at least some of the serial position effect changes that they showed and possibly for those from other experiments that have used $4 \mathrm{AFC}$ procedures (e.g., Korsnes \& Magnussen, 1996; Korsnes, Magnussen, \& Reinvang, 1996). They were quick, however, to point out that it was unclear how such response bias factors might be operating in same/different procedures, such as those of the present article.

In the $4 \mathrm{AFC}$ task, even if the subject thinks that the test item was not in the list, it still must guess a particular position. Thus, one source of guessing would seem to be from subjects forgetting that the item was in the list but being forced to guess. By contrast, in the same/different task, the subject responds different (i.e., not in the list) when it forgets that the item was in the list. There is also a second source of guessing that is peculiar to the
4AFC task. Subjects might remember that the item was in the list but forget its position. This second source of forgetting is not a factor in same/different tasks. In same/ different tasks, when the subject decides an item was in the list, it responds same, regardless of list position. Thus, there are two sources of guessing peculiar to $4 \mathrm{AFC}$ tasks that may be substantial and most likely would be confounded. Neither sources of guessing nor their associated response biases would seem to be a factor in same/ different tasks. It is difficult to imagine how any residual guessing in the same/different tasks of the present article could produce the substantial serial position differences and changes with retention interval.

List initiation and primacy effects. It was hypothesized that the primacy effects shown for rhesus monkey visual memory were due to artifacts of the monkeys' initiating lists and thereby drawing disproportionate attention to the first list items (D. Gaffan, 1983). Changes in primacy effects with retention interval under the same conditions of list initiation are contrary to this hypothesis and make it an unlikely explanation (Wright, 1994; Wright, Santiago, \& Sands, 1983). But the hypothesis was repeated without recognizing these contrary results $(\mathrm{E}$. A. Gaffan, 1992). Recent evidence clearly contradicts this hypothesis. Primacy effects have been shown under conditions in which rhesus monkeys did not initiate visual lists (Castro \& Larsen, 1992), capuchin monkeys did not initiate visual lists (Wright, in press-b), and rhesus monkeys did not initiate auditory lists (Wright, 1998; Wright $\&$ Rivera, 1997). In addition, the changes in primacy effects (and recency effects) with retention interval were virtually identical under both conditions for the capuchin's visual memory and the rhesus's auditory memory (Wright, 1998, in press-b). The list initiation hypothesis appears untenable. All relevant evidence (of which I am aware) contradicts it, and none supports it.

\section{The Teleology of Opposite-Shaped \\ Serial Position Functions}

Speculative as it may be, the issue of what possible purpose might be served by opposite-shaped serial position functions does arise.

From a practical standpoint, there should be advantages to coding items both visually and auditorially, beyond any advantages to redundant coding in the same modality. Opposite-shaped serial position functions (e.g., Figure 8) show that, when visual memory is poor (e.g., first items at 0 -sec delay), auditory memory for these items will be good. When auditory memory is poor (e.g., first items at long delays), visual memory for these items will be good.

There is considerable evidence that humans do crossmodality code. We frequently pronounce or silently mouth visual material (see, e.g., Crowder, 1983). We often visualize auditory material, such as environmental sounds or words (see, e.g., Campbell \& Dodd, 1980). If humans have opposite-shaped serial position functions, like monkeys, the cross-modality coding should help overall mem- 
ory. Indeed, one of the problems in testing pure visual or pure auditory memory in humans may be cross-modality coding.

From the standpoint of monkeys, cross-modality coding is unlikely, at least in the experimental setting. Monkeys do not readily code items in this experimental setting (Neiworth \& Wright, 1994). Active processing of memory that is dependent on coding (e.g., rehearsal) is not a behavior in which monkeys engage (Cook et al., 1991). These different-shaped serial position functions could possibly be related to the different learning requirements imposed by different modalities. Learning has been shown to be better when visual stimuli are associated with food and auditory stimuli are associated with danger, rather than the other way around (see, e.g., Shapiro, Jacobs, \& LoLordo, 1980).

Consider the visual serial position functions shown in Figure 8. If an animal has been having good luck foraging for food in some patch, it will need to remember to continue feeding in such patches (visual recency, short delay). On the other hand, if an animal feeds in a depleting patch (e.g., berries that ripen in the morning and are depleted as the day wears on), the animal will need to remember to go to this patch first thing in the morning after an overnight delay (visual primacy, long delay). Now consider auditory memory. If an animal hears a danger sound, it will need to remember the starting point of the sound (auditory primacy, short delay) to determine whether the sound (e.g., one made by a predator) is coming toward it and, of course, in which direction to escape. On the other hand, if an animal hears a danger sound but the sound stops, it needs to remember where the sound was last heard. Even after a long period of silence, it needs to remember where the sound was last heard (auditory recency, long delay) in order to avoid the spot where a potential predator might be hiding.

\section{Dissociations and the Modal Model}

The view that primacy and recency effects result from different time courses of PI and RI is different from the view that primacy and recency effects represent different memory processes. Yet, there is considerable evidence to support a claim that serial position primacy and recency effects represent different memory processes. Some of this evidence comes from behavioral studies showing dissociations of primacy and recency effects. For example, the recency effect can be selectively diminished and eventually eliminated by delaying recall (see, e.g., Gardiner, Thompson, \& Maskarinec, 1974; Glanzer \& Cunitz, 1966; Postman \& Phillips, 1965; Roediger \& Crowder, 1975) or recognition (see, e.g., Korsnes, 1995; Korsnes \& Gilinsky, 1993; Neath, 1993b; Neath \& Knoedler, 1994; Wright et al., 1985). The primacy effect can be selectively diminished by fast presentation rates (Glanzer \& Cunitz, 1966), low word frequency (Sumby, 1963), larger number of language categories in the list (Tulving \& Colotla, 1970), long list lengths (Murdock, 1962), or alcohol intoxication (Jones, 1973) and is eliminated in mental retardation (Belmont \& Butterfield, 1971). From neurobiological studies, the recency effect can be selectively diminished and, in some cases, eliminated by damage to the prefrontal cortex (see, e.g., Kesner, 1985), left-posterior temporal lobe (Saffran \& Marin, 1975; Weiskrantz, 1987), or injections of diazepam (Castro, 1995). The primacy effect has been shown to be selectively eliminated by lesions to the hippocampus and rhinal cortex (Kesner, Crutcher, \& Beers, 1988; Kesner \& Novak, 1982) or injections of atropine (Castro, 1997). In both the diazepam and atropine studies (Castro, 1995, 1997), the degree of diminution of the primacy or the recency effect was shown to be dose dependent.

A common, some might say obvious, interpretation of these process dissociation results is that there are two memory processes that can be selectively eliminated, resulting in a double dissociation (but see Crowder, 1989). One could make a case for different storage sites for the two memory processes. It could be argued that the site of memory represented by the recency effect, possibly STM, would be the temporal lobe and the prefrontal cortex (Kesner, 1985; Saffran \& Marin, 1975; Weiskrantz, 1987). In a like manner, the site of memory represented by the primacy effect, possibly LTM, could be argued to be the hippocampus and the rhinal cortical areas (Kesner et al., 1988; Kesner \& Novak, 1982). These results and their interpretation lend support to models and theories of how memory works and how STM and LTM are related.

Perhaps the theory that has had the greatest impact on the concepts of STM and LTM is the dual-store or modal model (see, e.g., Atkinson \& Shiffrin, 1968; Waugh \& Norman, 1965). According to this model, rehearsal of items maintained in an STM buffer moves them to LTM and, thereby, produces the primacy effect. But there is a growing body of evidence that makes such a memory framework, and possibly even the concepts of LTM and STM, untenable (see, e.g., Crowder, 1993; Greene, 1992). Among such evidence would be the long-term recency effects shown by increasing delays between memory items (see, e.g., Glenberg, Bradley, Kraus, \& Renzaglia, 1983), placing distractor activity between memory items (see, e.g., Bjork \& Whitten, 1974), having subjects recall names of presidents (Roediger \& Crowder, 1976), or having pub patrons recall rugby games (Baddeley \& Hitch, 1977). One could raise similar concerns regarding primacy effects and LTM. The auditory primacy effect disappears after a few seconds of retention interval. Should this be called short-term primacy? If so, there would be all combinations (and little value) of these terms: shortterm primacy, long-term primacy, short-term recency, and long-term recency.

Particularly damning for the modal model is that auditory primacy is present immediately and auditory recency is absent. How can there be LTM before STM, particularly since LTM is supposed to evolve from STM? So, if the STM/LTM framework is incorrect, what kinds of memory are represented by the primacy and recency effects of the serial position function? Some time ago it 
was said that the primacy effect "maintains its reputation as the Chinese puzzle of verbal learning" (Tulving \& Madigan, 1970, p. 454). That statement was made over 25 years ago, when most memory researchers were secure in their belief that the recency effect represented STM. Today, it seems that there is little or no agreement as to the nature of memory represented by the recency effect (see, e.g., Crowder, 1993). Thus, we have not one but two puzzles.

The dissociation studies, on the one hand, indicate that primacy and recency effects represent different memory processes; on the other hand, identification of these processes remains elusive. The conclusion from the dissociation experiments - that primacy and recency effects are selectively eliminated and, therefore, represent different memory processes - may itself contribute to maintaining these puzzles. There is another possibility, one that leads to a different view of serial position primacy and recency effects.

\section{The Possibility of Time Course Changes}

The evidence that primacy and recency effects change with retention interval and that different species have somewhat different time courses for these changes (e.g., Figure 2) suggests the possibility that time courses might be altered. For example, consider the Castro (1997) experiment. Rhesus monkeys were tested with six-item lists in a visual SPR procedure similar to that used by Sands and Wright (1980a, 1980b). Pictures were presented for $3 \mathrm{sec}$, with a 1 -sec ISI, and tests were conducted at a single retention interval of $1 \mathrm{sec}$. Castro (1997) showed a selective dose-dependent effect of atropine sulfate on the primacy effect relative to baseline and vehicle (atropine solvent) control. The primacy effect fell from $90 \%$ correct at the lowest dose $(0.2 \mathrm{mg} / \mathrm{kg})$ to chance or $50 \%$ correct at the highest dose $(0.4 \mathrm{mg} / \mathrm{kg})$. The recency effect, by contrast, remained close to perfect performance at all doses. The interpretation was a dissociation of the (memory) component that produced the primacy effect.

An alternative interpretation is that the time course of the primacy effect might have been slowed. The consequences of slowing the time course of the primacy effect could mimic a selective dissociation, because its appearance would be delayed. Furthermore, if the time course were dose dependent, the results would mimic a dosedependent selective dissociation. I am not aware of any direct evidence of primacy or recency effect time course manipulations, but evidence from timing studies may be relevant. Memory for a particular time interval has been shown to be manipulable by cholinergics, whereas the internal clock itself has been shown to be manipulable by dopaminergics (see, e.g., Meck, 1996; Meck \& Church, 1987). Atropine is a cholinergic drug. Atropine was shown to slow memory for time intervals, and, thus, time intervals were consistently remembered (by rats) as being longer than they actually were. This slowing of memory by the drug atropine was dose dependent, as was the dissipation of primacy in the Castro (1997) study. Whether this time interval slowing of memory translates into time course slowing of the primacy effect remains to be seen. If so, there could be some important ramifications. From a neuroanatomical standpoint, brain lesions might not eliminate storage sites for STM or LTM. Instead, lesions might alter the way in which memories interact (e.g., interference) and, hence, their time courses.

The possibility that the time courses for primacy and recency may be manipulated is testable. Perhaps procedures similar to those of this article would be most suitable: short lists of 4-5 items to study changes in primacy as well as recency effects; single-item recognition tests following each list to control retention time; different retention values to evaluate the time course of primacy and recency changes; and monkeys that, unlike humans, do not cross-modality code, thereby allowing visual and auditory memory to be separately studied. If true, such an explanation might be instrumental in solving the puzzle of what aspects of memory are being manipulated in dissociation experiments and why recency is sometimes long-term, and why primacy is sometimes short-term. These manipulations, along with our everyday memories about rugby games, presidents' names, Olympic game winners, and Christmas celebrations, for example, may be due to context-specific time courses with their associated primacy and recency effects for these special contextdependent serial memories.

\section{REFERENCES}

Atkinson, R. C., \& Shiffrin, R. M. (1968). Human memory: A proposed system and its control processes. In K. W. Spence \& J. T. Spence (Eds.), The psychology of learning and motivation (Vol, 2, pp. 89105). New York: Academic Press.

Baddeley, A. D., \& Hitch, G. J. (1977). Recency reexamined. In S. Dornic (Ed.), Attention and performance VI (pp. 647-667). Hillsdale, NJ: Erlbaum.

Belmont, J. M., \& Butterfield, E. C. (1971). Learning strategies as determinants of memory deficiencies. Cognitive Psychology, 2, 411-420.

BjoRk, R. A., \& Whitten, W. B. (1974). Recency-sensitive retrieval processes in long-term free recall. Cognitive Psychology, 6, 173-189.

Bolhuis, J. J., \& van Kampen, H. S. (1988). Serial position curves in spatial memory of rats: Primacy and recency effects. Quarterly.Journal of Experimental Psychologv, 40, 135-149.

BriggS, G. E. (1954). Acquisition, extinction, and recovery functions in retroactive inhibition. Journal of Experimental Psychology, 47, 285-293

Buchanan, J. P., Gill, T. V., \& Braggio, J. T. (1981). Serial position and clustering effects in chimpanzee's "free recall." Memorn \& Cognition, 9, 651-660.

Campbell, R., \& Dodn, B. (1980). Hearing by eye. Quarterly Journal of Experimental Psvchologv, 32, 85-99.

Castro, C. A. (1995). Primacy and recency effects in rhesus monkeys (Macaca mulatta) using serial probe recognition task: I. Effects of diazepam. Psvchopharmacology, 119, 421-427.

Castro, C. A. (1997). Primacy and recency effects in rhesus monkeys (Macaca mulatta) using a serial probe recognition task: II. Effects of atropine sulfate. Behavioral Neuroscience, 111. 676-682.

Castro, C. A., \& Larsen, T. (1992). Primacy and recency effects in nonhuman primates. Joumal of Experimental Psychology. Animal Behavior Processes, 18, 335-340. 
CoOK, R. G., Wright, A. A., \& SANDS, S. F. (1991). Interstimulus interval and viewing time effects in monkey list memory. Animal Learning \& Behavior, 19, 153-163.

CRaIK, F. I. M. (1970). The fate of primary memory items in free recall. Journal of Verbal Learning \& Verbal Behavior, 9, 143-148.

Crowder, R. G. (1969). Behavioral strategies in immediate memory. Journal of Verbal Learning \& Verbal Behavior, 8, 524-528.

CROWDER, R. G. (1976). Principles of learning and memory. Hillsdale, NJ: Erlbaum.

Crowder, R. G. (1983). The purity of auditory memory. Philosophical Transactions of the Royal Society of London: Series B, 302, 251-265.

Crowder, R. G. (1989). Modularity and dissociations in memory systems. In H. L. Roediger III \& F. I. M. Craik (Eds.), Varieties of memory and consciousness: Essays in honour of Endel Tulving (pp. 271294). Hillsdale, NJ: Eribaum.

CROWDER, R. G. (1993). Short-term memory: Where do we stand? Memory \& Cognition, 21, 142-145.

Crowder, R. G., \& Neath, I. (1991). The microscope metaphor in human memory. In W. E. Hockley \& S. Lewandowsky (Eds.), Relating theory and data: Essays on human memory in honor of Bennet $B$. Murdock, Jr. (pp. 111-125). Hillsdale, NJ: Erlbaum.

DEvine, J. V., \& JONES, L. C. (1975). Matching-to-successive samples: A multiple-unit memory task with rhesus monkeys. Behavior Research Methods \& Instrumentation, 7, 438-440.

Ebbinghaus, H. E. (1902). Grundzuge der Psychologie [Basic psychology]. Leipzig: Von Veit.

EDDv, D. R. (1973). Memory processing in Macaca speciosa: Mental processes revealed by reaction time experiments. Unpublished doctoral dissertation. Carnegie Mellon University.

Foucault, M. (1928). Les inhibitions internes de fixation. Année Psychologique, 29, 92-112.

GaFFAN, D. (1977). Recognition memory after short retention intervals in fornix-transected monkeys. Quarterly Journal of Experimental Psychology, 29, 577-588.

GAFFAN, D. (1983). A comment on primacy effects in monkeys' memory for lists. Animal Learning \& Behavior, 11, 144-145.

Gaffan, E. A. (1992). Primacy, recency, and the variability of data in studies of animals" working memory. Animal Learning \& Behavior, 20, 240-252.

Gardiner, J. M., Thompson. C. P., \& Maskarinec, A. S. (1974). Negative recency in initial free recall. Journal of Experimental Psychol ogy, 103, 71-78

GlaNZER, M. (1972). Storage mechanisms in recall. In G. H. Bower (Ed.), The psychology of learning and motivation (Vol. 5, pp. 129193). New York: Academic Press

Glanzer, M., \& CunitZ, A. R. (1966). Two storage mechanisms in free recall. Journal of Verbal Learning \& Verbal Behavior, 5, 351-360.

GleNBERG, A. M. (1987). Temporal context and memory. In D. S. Gorfein \& R. R. Hoffman (Eds.), Memory and learning: The Ebbinghaus centennial conference (pp. 173-190). Hillsdale, NJ: Erlbaum.

Glenberg, A. M., Bradley, M. M., Kraus, T. A., \& Renzaglia, G. J. (1983). Studies of the long-term recency effect: Support for a contextually guided retrieval hypothesis. Journal of Experimental Psychology: Learning, Memory, \& Cognition, 9, 231-255.

Glenderg, A. M., \& SWANSON, N. G. (1986). A temporal distinctiveness theory of recency and modality effects. Journal of Experimental Psychology: Learning, Memory, \& Cognition, 12, 3-15.

GorFEIN, D. S. (1987). Explaining context effects on short-term memory. In D. S. Gorfein \& R. R. Hoffman (Eds.), Memory and learning: The Ebbinghaus centennial conference ( $\mathrm{pp}$. 153-172). Hillsdale, NJ: Erlbaum.

Graefe, T. M., \& Watkins, M. J. (1980). Picture rehearsal: An effect of selectively attending to pictures no longer in view. Journal of Experimental Psychology: Human Learning \& Memory, 6, 156-162.

GreENE, R. L. (1986). Sources of recency effects in free recall. Psychological Bulletin, 99, 221-228.

GREENE, R. L. (1992). Human memory. Hillsdale, NJ: Erlbaum.

Harper, D. N., McLean, A. P., \& Dalrymple-Alford, J. C. (1993). List item memory in rats: Effects of delay and delay task. Journal of Experimental Psychology: Animal Behavior Processes, 19, 307-316.

Harrison, J. M., Iversen, S. D., \& Pratt, S. R. (1977). Control of responding by location of auditory stimuli: Adjacency of sound and response. Journal of the Experimental Analysis of Behavior, 28, 243-251.

HuLl, C. L. (1935). The conflicting psychologies of learning-a way out. Psychological Review, 42, 491-516.

InTRAub, H. (1980). Presentation rate and the representation of briefly glimpsed pictures in memory. Journal of Experimental Psychology: Human Learning \& Memory, 6, 1-12.

Jitsumori, M., Wright, A. A., \& Cook, R. G. (1988). Long-term proactive interference and novelty enhancement effects in monkey list memory. Journal of Experimental Psychology: Animal Behavior Processes, 14, 146-154.

JoNES, B. M. (1973). Memory impairment on the ascending and descending limbs of the blood alcohol curve. Journal of Abnormal Psychology, 82, 24-32.

KePPEL, G., \& UNDERWoOd, B. J. (1962). Proactive inhibition in shortterm retention of single items. Journal of Verbal Learning \& Verbal Behavior, 1, 153-161.

KerR, J., WARD, G., \& Avons, S. E. (1998). Response bias in visual serial order memory. Journal of Experimental Psychology: Learning, Memory, \& Cognition, 24, 1316-1323.

KeSNER, R. P. (1985). Correspondence between humans and animals in coding of temporal attributes: Role of hippocampus and prefrontal cortex. In D. S. Olton, E. Gamzu, \& S. Corkin (Eds.), Memory dysfunctions: An integration of animal and human research from preclinical and clinical perspectives (Annals of the New York Academy of Sciences, Vol. 444, pp. 122-136). New York: New York Academy of Sciences.

Kesner, R. P., Crutcher, K. A., \& Beers, D. (1988). Serial position curves: Dorsal hippocampal formation and medial septum. Brain Research, 454, 219.

KeSNER, R. P. \& NovaK, J. M. (1982). Serial position curve in rats: Role of the dorsal hippocampus. Science, 218, 173-175.

KoRSNES, M. S. (1995). Retention intervals and serial list memory. Perceptual \& Motor Skills, 80, 723-73!

KonSNes, M. S., \& GilinsKy, S. A. (1993). Aging and serial list picture memory. Perceptual \& Motor Skills, 76, 1011-1014.

KoRSNes, M. S., \& MAGnussen, S. (1996). Age comparisons of serial position effects in short-term memory. Acta Psychologica, 94, 133-143.

Korsnes, M. S., Magnussen, S., \& Reinvang, I. (1996). Serial position effects in visual short-term memory for words and abstract spatial patterns. Scandinavian Journal of Psychology, 37, 62-73.

Madigan, S. A., \& McCabe, L. (1971). Perfect recall and total forgetting: A problem for models of short-term memory. Journal of Verbal Learning \& Verbal Behavior, 10, 101-106.

MECK, W. H. (1996). Neuropharmacology of timing and time perception. Cognitive Brain Research, 3, 227-242.

MeCK, W. H., \& ChURCh, R, M. (1987). Cholinergic modulation of the content of temporal memory. Behavioral Neuroscience, 101, 457-464.

Murdock, B. B., JR. (1960). The distinctiveness of stimuli. Psychological Review, 67, 16-31

Murdock, B. B., JR. (1962). The serial position effect of free recall. Journal of Experimental Psychologv, 64, 482-488.

NAIRNE, J. S. (1990). A feature model of immediate memory. Memory \& Cognition, 18, 251-269.

Neath, I. (1993a). Contextual and distinctive processes and the serial position function. Journal of Memory \& Language, 32, 820-840.

NeATH, I. (1993b). Distinctiveness and serial position effects in recognition. Memory \& Cognition, 21, 689-698.

NeATh, I., \& KNOEdLER, A. J. (1994). Distinctiveness and serial position effects in recognition and sentence processing. Journal of Memory \& Language, 33, 776-795.

Neiworth, J. J., \& WRight, A. A. (1994). Monkeys (Macaca mulatta) learn category matching in a nonidentical same/different task. Journal of Experimental Psychology: Animal Behavior Processes, 20, 429-435. Postman, L., \& Phillips, L. (1965). Short-term temporal changes in freerecall. Quarterly Journal of Experimental PSychology, 17, 132-138.

Postman, L., S TARK, K., \& Fraser, J. (1968). Temporal changes in interference. Journal of Verbal Learning \& Verbal Behavior, 7, 672-694.

Postman, L., Stark, K., \& Henschel, D. (1969). Conditions of recovery after unlearning. Journal of Experimental Psychology: 82. (1, Pt. 2), 1-24. 
Proc tor, R. W. (1983). Recognition memory for pictures as a function of poststimulus interval: An empirical clarification of existing literature. Journal of Experimental Psichologi: Learning, Memorn, \& Cognition, 9, 256-262.

Reed, P., Croft, H., \& Yeomans, M. (1996). Rats' memory for serially presented novel flavours: Evidence for non-spatial primacy effects. Quarterly Journal of Experimental Psychology, 49B, 174-187.

RoBerTS, W. A., \& Kraemer, P. J. (1981). Recognition memory for lists of visual stimuli in monkeys and humans. Animal Learning \& Behavior, 9. 587-594.

Roediger, H. L., III, \& Crowder, R. G. (1975). Spacing of lists in free recall. Journal of Verbal Learning \& Verbal Behavior, 14, 590-602.

ROEDIGER, H. L., III, \& CROWDER, R. G. (1976). A serial position effect in recall of United States presidents. Bulletin of the Psychonomic Societv, 8, 275-278.

Rundus, D. (1971). Analysis of rehearsal processes in free recall. Journal of Experimental Psychology, 89, 63-77.

SAFFRAN, E., \& MARIN. O. (1975). Immediate memory for work lists and sentences in a patient with deficient auditory short-term memory. Brain \& Language, 2, 420-433

SANDS, S. F., \& Wright, A. A. (1980a). Primate memory: Retention of serial list items by a rhesus monkey. Science, 209, 938-940.

SANDS, S. F., \& WRIGHT, A. A. (1980b). Serial probe recognition performance by a rhesus monkey and a human with 10 - and 20 -item lists Journal of Experimental Psychology: Animal Behavior Processes, 6, 386-396.

Santiago, H. C., \& Wright, A. A. (1984). Pigeon memory: Same/ different concept learning, serial probe recognition acquisition and probe delay effects in the serial position function. Journal of Experimental Psychology: Animal Behavior Processes, 10, 498-512.

Shand, M. A., \& Klima, E. S. (1981). Nonauditory suffix effects in congenitally deaf signers of American sign language. Journal of Experimental Psychology: Human Leaming \& Memory, 7, 464-474.

Shapiro, K. L., Jacobs, W. J., \& Lolordo, V. M. (1980). Stimulusreinforcer interactions in Pavlovian conditioning of pigeons: Implications for selective associations. Animal Learning \& Behavior, 8 , 586-594.

Sumby, W. H. (1963). Word frequency and serial position effects. Journal of Verbal Learning \& Verbal Behavior, 1, 443-450.

Tulving, E. (1968). Theoretical issues in free recall. In T. R. Dixon \& D. L. Horton (Eds.), Verbal behavior and general behavior theory (pp. 2-36). Englewood Cliffs, NJ: Prentice-Hall.

Tulving, E., \& Colotla, V. (1970). Free recall of trilingual lists. Cognitive Psychologi, 1, 86-98.

Tulving, E., \& Madigan, S. A. (1970). Memory and verbal learning. Annual Review of Psichology, 21, 437-484.

UNDERWOOD, B. J. (1948a). Retroactive and proactive inhibition after five and forty-eight hours. Journal of Experimental Psychology, 38, 29-38.
UNDERWOOD, B. J. (1948b). "Spontaneous recovery" of verbal associations. Journal of Experimental Psychology, 38, 29-38.

WATKINS, M. J. (1989). Willful and nonwillful determinants of memory. In H. L. Roediger III \& F. I. M. Craik (Eds.), Varieties of memory and consciousness: Essays in honour of Endel Tulving (pp. 59-71). Hillsdale, $\mathrm{NJ}$ : Erlbaum.

Watkins, M. J., \& GRAEFE, T. M. (1981). Delayed rehearsal of pictures. Journal of Verbal Learning \& Verbal Behavior, 20, 176-288.

Waugh, N. C., \& Norman, D. A. (1965). Primacy memory. Psychological Review, 72, 89-104.

WEISKRANTZ, L. (1987). Neuroanatomy of memory and amnesia: A case for multiple memory systems. Human Neurobiology, 6, 93-105.

Wright, A. A. (1994). Primacy effects in animal memory and human nonverbal memory. Animal Learning \& Behavior, 22, 219-223.

Wright, A. A. (1998). Auditory list memory in rhesus monkeys. Psychological Science, 9, 91-98.

WRIGHT, A. A. (in press-a). Auditory list memory and interference processes in monkeys. Journal of Experimental Psychology: Animal Behavior Processes.

WRIGHT, A. A. (in press-b). Memory processing of visual lists by capuchin monkeys. Journal of Comparative Psychology.

Wright, A. A., Cook, R. G., Rivera, J. J., Shyan, M. R., Neiworth, J. J., \& Jitsumori, M. (1990). Naming, rehearsal, and interstimulus interval effects in memory processing. Journal of Experimental Psychology: Learning, Memory, \& Cognition, 16, 1043-1059.

Wright, A. A., \& RiverA, J. J. (1997). Memory of auditory lists by rhesus monkeys (Macaca mulatta). Journal of Experimental Psychology: Animal Behavior Processes, 23, 1-9.

Wright, A. A., Santiago, H. C., \& Sands, S. F. (1983). On the nature of the primacy effect in memory processing: A reply to Gaffan. Animal Learning \& Behavior, 11, 148-150.

Wright, A. A., Santiago, H. C., \& Sands, S. F. (1984). Monkey memory: Same/different concept learning, serial probe acquisition, and probe delay effects. Journal of Experimental Psvchology: Animal Behavior Processes, 10, 513-529.

Wright, A. A., Santiago, H. C., Sands, S. F., Kendrick, D. F., \& CoOK, R. G. (1985). Memory processing of serial lists by pigeons, monkeys, and people. Science, 229, 287-289.

Wright, A. A., Shyan M. R., \& Jitsumori, M. (1990). Auditory same/different concept learning by monkeys. Animal Learning $\&$ Behavior, 18, 287-294.

Wright, A. A., Urcuioli, P. J., \& Sands, S. F. (1986). Proactive interference in animal memory research. In D. F. Kendrick, M. Rilling, \& R. Denny (Eds.), Theories of animal memory (pp. 101-125). Englewood Cliffs, $\mathrm{NJ}$ : Erlbaum.

(Manuscript received December 31, 1997; revision accepted for publication June 30, 1998.) 